\title{
Spatio-Temporal Assessment of the Performance of March to May 2020 Long Rains and Its Socio-Economic Implications in Northern Coast of Tanzania
}

\author{
Kombo Hamad Kai ${ }^{1}$, Agnes Laurence Kijazi ${ }^{2}$, Sarah E. Osima ${ }^{2}$, Habiba Ismail Mtongori², \\ Makame Omar Makame1, Hafidh Juma Bakari'1, Omar Asya Hamad1 \\ ${ }^{1}$ Tanzania Meteorological Agency (TMA), Institute of Marine Sciences (IMS), University of Dar es Salam (UDSM), Zanzibar, \\ Tanzania \\ ${ }^{2}$ Tanzania Meteorological Authority (TMA) Headquarters, Ubungo Plaza, Dar es Salaam, Tanzania \\ Email: Kombokai68@gmail.com, Agness.kijazi@meteo.go.tz, sarah.osima@meteo.go.tz, habiba.mtongori@meteo.go.tz, \\ hafidh.bakari@meteo.go.tz, asyoo@yahoo.com
}

How to cite this paper: Kai, K.H., Kijazi, A.L., Osima, S.E., Mtongori, H.I., Makame, M.O., Bakari, H.J. and Hamad, O.A. (2021) Spatio-Temporal Assessment of the Performance of March to May 2020 Long Rains and Its Socio-Economic Implications in Northern Coast of Tanzania. Atmospheric and Climate Sciences, 11, 767-796.

https://doi.org/10.4236/acs.2021.114045

Received: July 26, 2021

Accepted: October 26, 2021

Published: October 29, 2021

Copyright $\odot 2021$ by author(s) and Scientific Research Publishing Inc. This work is licensed under the Creative Commons Attribution International License (CC BY 4.0).

http://creativecommons.org/licenses/by/4.0/

(c) (i) Open Access

\begin{abstract}
The spatio-temporal analysis of the performance of the March to May (MAM) 2020 rainfall and its societal implications to Northern Coastal Tanzania (NCT) including Zanzibar was investigated. The uniqueness of the October to December, 2019 (OND) rainfall and the extension of the January to February, 2020 rainfall in Zanzibar which coincided with MAM 2020 rainfall was among the issues which prolonged MAM 2020 rainfall in NCT and Zanzibar. The National Center for Environmental Prediction (NCEP) in collaboration with National Center for Atmospheric Research (NCAR). Reanalysis 1 datasets of $u$ (zonal) and $v$ (meridional) winds, sea surface temperatures anomalies, relative humidity, amount of precipitable water and ocean net flux were analyzed. Other datasets include the Tanzania Meteorological Authority (TMA) observed rainfall records, maximum and minimum temperatures. Moreover, TMA and Intergovernmental Climate Prediction and Analysis Center (ICPAC). MAM 2020 rainfall and temperature forecast reports were interpreted. Gridded and observed datasets were calculated into monthly and seasonal averages. As for observed data, long-term monthly and MAM percentage changes were calculated. Besides, the correlation between rainfall anomalies with an area-averaged $\mathrm{SST}_{\mathrm{A}}$ for defined regions and stations in Zanzibar was performed. Lastly, the calculated monthly and seasonal rainfall was compared to MAM periods of 2016, 2017, 2018 and 2019. Results revealed that consecutive
\end{abstract}


five MAM seasonal rainfall was among the highest ones in records with that of 2020 being exceptional. These MAM seasons had percentage contribution ranged from $68 \%-212 \%, 150 \%-304 \%, 22 \%-163 \%$ and $57 \%-170 \%$ for stations in Zanzibar and 130\% - 230\%, 57\% - 168\% and 230\% - 706\% for NCT station, respectively. Compared to previous MAM seasons of 2016-2019, MAM 2020 rainfall season was spatially well distributed in our study area with rainfall ranging from 1200 to $2100 \mathrm{~mm}$ and up to 900 in most Zanzibar and NCT stations. Indeed, the study revealed that the observed highest rainfall and flooding was enhanced by wet seasons of MAM 2019, OND 2019 and DFJ (2019-2020). Other dynamics which accelerated MAM 2020 rainfall were the higher $\mathrm{SST}_{\mathrm{A}}$ ranged from $0.5^{\circ} \mathrm{C}-1.5^{\circ} \mathrm{C}$ and $1.5^{\circ} \mathrm{C}-2.5^{\circ} \mathrm{C}$ over Southwestern Indian Ocean (SWIO) and coastal Tanzania and the increased trend of area-averaged $\mathrm{SST}_{\mathrm{A}}$ on various SWIO blocks. Besides, parameters including Rhum, PWR and wind regimes were supporting the MAM 2020 rainfall. The socio-economic implications of these rains were strong and spatially well distributed in Zanzibar. For instance, a death toll of about 10 people, a great number of road culverts were washed away, and about 3600 houses were fallen or damaged, leading to a significant number of homeless people. As for NCT, the catastrophes include loss of lives, increased water levels over Lake Victoria leading to flooded islands and re allocation of more than 1000 people. In Kenya, more than 116 people died and 40,000 people were displaced. Conclusively, the study has shown the uniqueness (i.e., strength and societal implications) of MAM 2020 compared to other seasons; hence more studies on understanding the factors affecting extreme rainfall seasons in East Africa are required.

\section{Keywords}

March to May 2020 Rainfall Assessment, Sea Surface Temperatures Anomalies $\left(\mathrm{SST}_{\mathrm{A}}\right)$ Assessments, Precipitable Water (PRW) and Ocean Net Flux, Relative Humidity

\section{Introduction}

The northern coastal and hinterland zones of Tanzania including Zanzibar are among the East African (EA) countries that largely depend on rain-fed agriculture for the sustainability of its economy [1]. Though practiced on a small scale and mainly by local peasants, agriculture in Zanzibar has a higher contribution of about 30.8\% to the Gross National Product (GNP) (OCGS, 2008) while as in mainland coastal areas agriculture is practiced on a large scale and hence employing a significant number of people. Irrespective of employing about $70 \%$ (42\% directly) (ZGS, 2007) of the labor force in Zanzibar, the planning and water resources management of this sector is faced by great challenges of climate variability and changes [2] [3] which results or posed major humanitarian concern and threats [3] as well as disrupting seasonal rainfall variability [4]. Both 
the NCT and Zanzibar lie on two wet distinct climate regimes of long rains (Masika) which take place from March to May (MAM) and short rains (Vuli) which normally occur from October to December. Masika is characterized with abundant rainfall governed by good spatial and temporal distribution, while Vuli rains are highly variability with less and poor spatial and temporal distribution [5] [6] [7] [8] [9]. The variability and changes of seasonal rainfall in wet and dry season results to floods and drought as remarked by [10] that of the seven most flood-prone countries in Africa, five are in eastern Africa. These floods in the region could be attributed to what was noted by [3] that Masika rainfall accounts for about $30 \%-60 \%$ of the mean annual rainfall in most parts of the region. Moreover, [3] noted that Masika rainfall demonstrates its importance to most sectors including agriculture, water, energy and other socio-economic sectors, which contributes to $85 \%$ of the climate-driven economic activity in Tanzania [5]. The occurrences of floods and droughts have increasingly negative impacts not only on agriculture, but also on the wide spectrum of human life. For instance, the rainfall variability for Masika (MAM) and Vuli (OND) of 2019 [9] and 2020 January to February (JF) off-season rainfall [11] indicted strong wetness conditions in Zanzibar and NCT areas leading to a number of socio-economical implications including death as noted by [9] that OND 2019 rainfall resulted into deaths of 3 people in Unguja, and a significant number of people were forced to leave their homes in many areas of Zanzibar and NCT. Indeed, [11] has noted that the December 2019 and JF 2020 off-season rainfall has resulted in significant impacts to the study areas. For instance, [11] noted that heavy rainfall and strong winds severe weather warning issued by TMA on $21^{\text {st }}$ to $22^{\text {nd }}$ December, 2019 [12] resulted in a significant number of impacts ranging from deaths, destruction of infrastructure, and even stranding of transportation in Dar es Salaam, Morogoro and Dodoma regions. Also, [13] and [1] [11] have shown that the main dynamic factors behind the 2019 OND heavy rainfall were the presence of positive phase of the Madden Julian Oscillation (MJO) and the enhanced positive phase of the Indian Ocean Dipole (IOD). These two studies agreed that 2019 OND rainfall over East Africa, NCT and Zanzibar, in particular, was the highest in history. Though no study has been conducted to assess the impacts of the MAM, 2019 seasonal rainfall in Tanzania in general, and NCT and Zanzibar in particular, but ICPAC and TMA forecast reports had foreseen the likelihood of having normal to above normal rainfall over the bimodal regime of Tanzania [14] and TMA Special Issue No. 21, 2019. The outcomes of these two forecasts as per the observation records from TMA (Zanzibar office) showed that the MAM 2019 rainfall season was among the wet ones with rainfall ranging from 1070.8 - $1223 \mathrm{~mm}$ (123\% and 127\% of the long term (1983-2019) mean for MAM in Unguja and Pemba (Zanzibar), respectively.

Following the wetness of three consecutive wet seasons of 2019 also the MAM, 2020 was forecasted to be exceptional wet in the sense that the ICPAC forecast report revealed northern Tanzania, NCT and Zanzibar was foreseen to experience wetter than normal conditions associated with early-onset as agreed by 
[15] that during wet years, the rains begin earlier and end later, while Southern Tanzania was forecasted to have late-onset conditions [16]. The TMA forecast report had gone for above-normal rainfall over the bimodal regime areas with early-onset conditions [17]. Observations show that like the 2019 OND, the MAM, 2020 rainfall season was characterized by an increased number of catastrophic events (e.g., deaths, damaging infrastructure). Though, reference [3] has analyzed the strength and impacts of the MAM, 2020 rainfall over the East African region but the effects of these MAM, 2020 rainfall NCT and to Zanzibar were not well covered. Reference [3] discussed Zanzibar as a single precipitation generation point that represents the average precipitation statistics of the entire two islands). Besides, apart from [3]-[18], and the two forecast reports (i.e., ICPAC and TMA), no other study has tried to investigate the temporal and spatial distribution of both the rainfall and the socio-economic impacts associated with MAM, 2020 rainfall in NCT and Zanzibar, also the dynamic and the reason behind the forecasted MAM 2020 heavy rainfall. Thus, this study aimed at understanding the dynamics of the MAM, 2020 rainfall, the strength and extent of its spatial and temporal distribution as well as its associated full spectrum of the socio-economic implications in NCT, and Zanzibar and Tanzania at large. This information (study findings) is of crucial importance in the development of strategies for minimizing the impacts of severe MAM rainfall such as Impacts Based Flood Forecasting Models (IBFFMs).

\section{Data and Methods}

\subsection{Study Site}

The study area covers the NCT and the two Islands of Zanzibar i.e. Unguja and Pemba (Figure 1) which is well discussed by [9] and [11] [19] The climate of Zanzibar during March to May is dominated with higher average temperatures and mostly wet conditions which are highly influenced by either normal to abnormal ocean atmosphere coupled events including tropical cyclones [8]. Normally the Masika rainfall in Tanzania (NCT) and Zanzibar in particular is dominated by the immigration of Inter tropical Convergence Zone (ITCZ) which enhances the fluctuation of tropical low pressure belt as well as fluctuation of pressure systems, southeasterly, southwesterly, easterlies among others [6] [7] [9]. The long-term average maximum temperature during March to May for Zanzibar ranged from $32.4^{\circ} \mathrm{C}$ for Unguja and $31.6^{\circ} \mathrm{C}$ for Pemba, while the minimum ranged from $33.0^{\circ} \mathrm{C}$ to $32.0^{\circ} \mathrm{C}$ for Unguja and Pemba, respectively. The two sister Islands of Unguja and Pemba are 35 and $56 \mathrm{~km}$ off the coast of mainland Tanzania (Figure 1). Pemba is dominated by low-lying areas whose highest point reaches an elevation $95 \mathrm{~m}$ while the highest point in Unguja reaches $119 \mathrm{~m}$ at Masingini area. The west and northwest of Unguja consists of several ridges rising above $60 \mathrm{~m}$ but nearly two-thirds of the south and east are low lying areas. These islands have both perennial and ephemeral rivers but Pemba has exceedingly higher river density than Unguja [20]. During the long rains seasons these rivers flood rapidly while during the dry season they flow low [20]. 


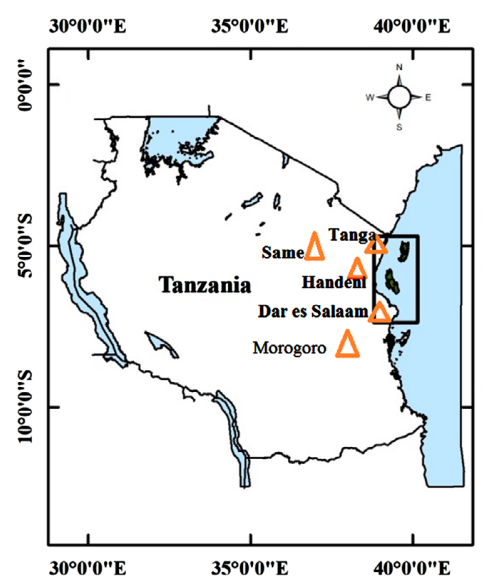

(a)

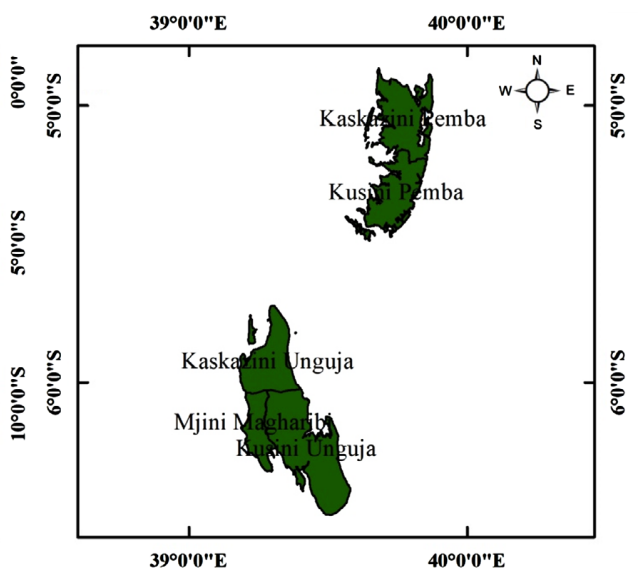

(b)

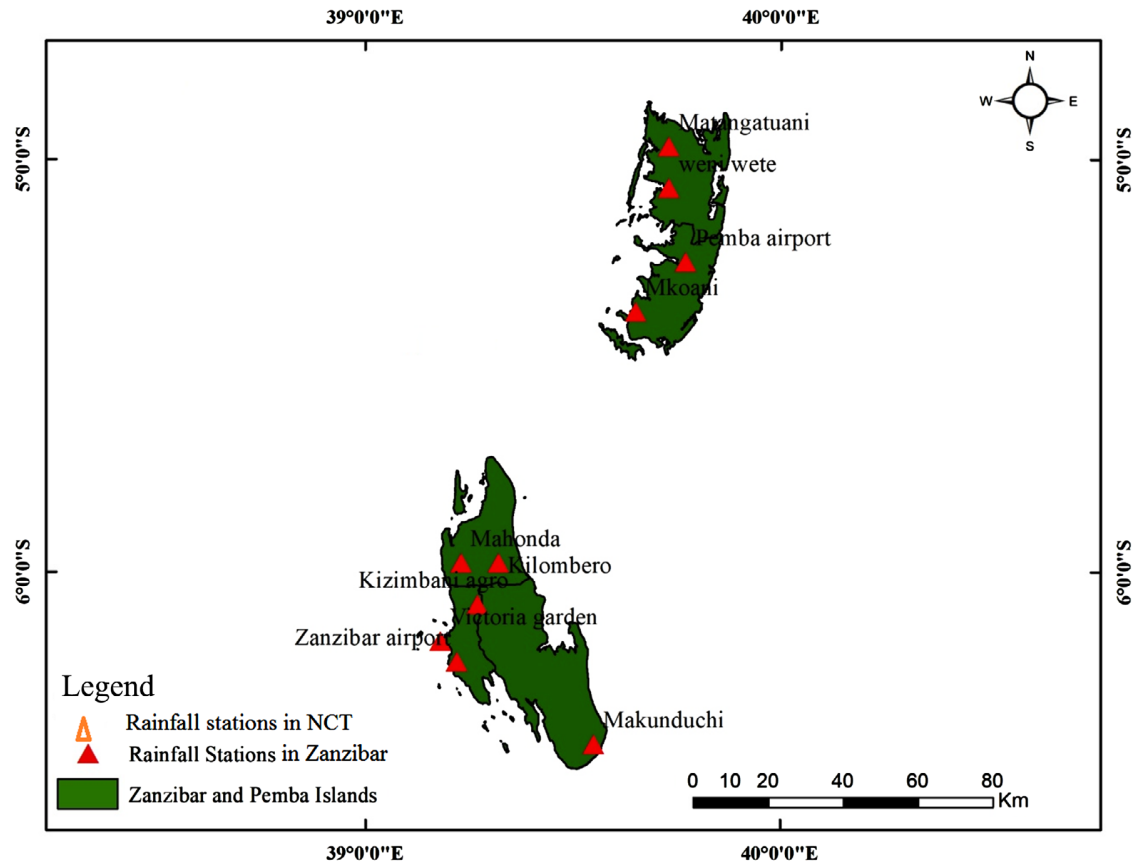

(c)

Figure 1. The study site, where (a) is the map of Tanzania; (b) two Islands of Zanzibar and Pemba; (c) selected stations for rainfall data during MAM, 2020 rainfall season (source: Institute of Marine Sciences layers).

\subsection{Datasets}

For finding the solutions of the aforementioned specific objectives and getting the insight on the extent to the atmospheric circulation patterns influences the heavy MAM rainfall, the NCEP)/NCAR reanalysis 1 datasets were used. The variables used include $\mathrm{u}$ and $\mathrm{v}$ winds at different levels (e.g. 850, 700, 500 and 200 $\mathrm{mb}$ ), the prercipitable water (hereafter PRW), relative humidity (here after Rhum) at $850-700 \mathrm{mb}$ as well as Outgoing Long wave Radiation (OLR) which maps the convective activates during the study period. All these data have a spatial resolution of $2.5^{\circ} \times 2.5^{\circ}$. Other used datasets includes the Global air-sea heat and momentum flux climatology from the Southampton Oceanography Centre (SOC 
GASC97) Ocean thermal heat energy/flux data [21]. Indeed, the Sea Surface Temperature Anomaly $\left(\mathrm{SST}_{\mathrm{A}}\right)$, the monthly and daily mean observed rainfall records acquired from TMA were used. The stations used to acquire these datasets for Zanzibar include Kisauni (Zanzibar airport), Victoria garden, Makunduchi, Kizimbani agromet, Kilombero and Mahonda, while for Pemba the stations include Mkoani, Karume (Pemba airport), Weni (Wete) and Matangatuani (Figure 1(c)). As for the NCT the used stations includes Dar es Salaam, Morogoro, Handeni, Tanga and Same respectively. Additionally, the aerial photograph maps, records of the affected areas, schools, peoples among others during the MAM, 2020 rainfall season was acquired from the Disaster Management Commission (DMC) of the Revolutionary Government of Zanzibar (RGoZ). Also the use of Radar and satellite rainfall datasets could increase the understanding of the spatial and temporal distribution of the MAM rainfall in NCT and Zanzibar.

\subsection{Methods}

Using the Grads soft ware, the selected gridded data $\left(\mathrm{SST}_{\mathrm{A}}\right.$, OLR, winds $(\mathrm{U}, \mathrm{V})$, PRW), Rhum) were customized to fit the study domain and period. Also the time average function in this software was used to calculate and map the seasonal and monthly averages of the gridded datasets. Using simple statistic (mean, percentage contribution among others) analysis the station observed datasets were processed, calculated into monthly mean, plotted and then analyzed. The Pearson double moment correlation [22] [23] was used to find the association (correlation i.e., to what significant level do the two influence each other) between the MAM, 2020 rainfall records from selected stations (Figure 1(c)) and climate parameters including $\mathrm{SST}_{\mathrm{A}}$, for the selected SWIO regions were conducted. The socio economic impact records (data) for the MAM 2020 rainfall collected from DMC for each area in Zanzibar and NCT were processed (filtering to remove the data collection errors and ambiguous records) and then calculated into monthly and seasonal averages, then plotted and analyzed. Mean percentage contribution and comparison of the strengths between the MAM, 2020 rainfall records and the past four MAM seasons of 2016, 2017, 2018 and 2019 was conducted. The comparison of the strength of the rainfall impacts data (e.g. broken or watered houses, among others) and rainfall over selected station was also conducted and discussed. Area average $\mathrm{SST}_{\mathrm{A}}$ over the selected area of SWIO basin and over Mozambican channel during the past 30 yrs consecutive MAM seasons (1990-2019) was extracted, calculated, plotted and analyzed. The data was plotted for MAM, 2020 as well as extracted for previous five MAMs (i.e. 5 consecutive MAM periods of 2016, 2017, 2018, 2019 and 2020) over the coastal waters of EA and over the northeastern Madagascar to observe the trend of the ocean warming during MAM periods. These regions include $10^{\circ}-12^{\circ} \mathrm{S}, 50^{\circ}-$ $80^{\circ} \mathrm{E}$ (hereafter Rs); $4^{\circ}-12^{\circ} \mathrm{S}, 45^{\circ}-80^{\circ} \mathrm{E}$ (hereafter Re); and $12^{\circ}-16^{\circ} \mathrm{S}, 39^{\circ}-$ $48^{\circ} \mathrm{E}$ (hereafter $\mathrm{Rm}$ ). The main argument behind the selection of these regions was: 1) to track the influence of southeasterly, easterly and southeasterly to wes- 
terly moisture flow (moisture flux); 2) In practice the MAM seasons for Tanzania and East Africa (EA) at large are affected by the maritime moisture influx from the selected regions. Also the Ocean thermal heat energy/flux data [21] which was intended to map the net ocean heat flux over the SWIO domain during MAM periods was calculated into monthly averages plotted and analyzed. Indeed, the observed rainfall (the measure of the strength of the MAM season) and damage (impacts associated to these seasonal rainfall) records were sorted and calculated into monthly and seasonal total and averages and compared with the long term averages and totals. Lastly the results were plotted analyzed, and then extensively discussed with reference to findings of other studies, and then conclusions and recommendations were drawn.

\section{Results}

\subsection{Monthly Mean $\mathrm{SST}_{\mathrm{A}}$ Variability during March to May, 2020}

The results of the $\mathrm{SST}_{\mathrm{A}}$ for MAM, 2020 presented in Figure 2 revealed higher $\mathrm{SST}_{\mathrm{A}}$ ranged from $1{ }^{\circ} \mathrm{C}-2.5^{\circ} \mathrm{C}$ over the Somali coast, whereas the entire EA coastal waters and Mozambican channel was under the influence of warm $\operatorname{SST}_{\mathrm{A}}$ ranged from $0.1^{\circ} \mathrm{C}-1.5^{\circ} \mathrm{C}$ (Figure $2(\mathrm{a})$ ). The only area which had lower $\mathrm{SST}_{\mathrm{A}}$ ranged from $-1^{\circ} \mathrm{C}-0^{\circ} \mathrm{C}$ over the SWIO was at the eastern and northeastern Madagascar. This indicates that most areas of SWIO areas were under warm conditions leading to enough moisture advection from the ocean to the western coast and hinterland areas. Moreover, results in Figure 2(a) shows that Pemba and coastal waters of Tanga was under higher $\operatorname{SST}_{\mathrm{A}}$ influence of $1^{\circ} \mathrm{C}-1.5^{\circ} \mathrm{C}$ while Unguja and Dar es Salaam coasts had a relative lower influence of $\mathrm{SST}_{\mathrm{A}}$ $\left(0.5^{\circ} \mathrm{C}-1^{\circ} \mathrm{C}\right)$. This could be attributed by Deep Ocean (bathymetric levels) at Pemba than at Unguja. Similar results holds for the April, 2020 (Figure 2(b)) except that the $\operatorname{SST}_{\mathrm{A}}$ strength over the EA coastal waters and Mozambican Channel was slightly reduced from $0.1^{\circ} \mathrm{C}-1.5^{\circ} \mathrm{C}$ to $0^{\circ} \mathrm{C}-1^{\circ} \mathrm{C}$, and that of Somali coast was reduce from $1^{\circ} \mathrm{C}-2.5^{\circ} \mathrm{C}$ to $0.5^{\circ} \mathrm{C}-1.5^{\circ} \mathrm{C}$ except for very few small locations. Indeed, the $\mathrm{SST}_{\mathrm{A}}$ over the northeastern and eastern Madagascar was strengthened and penetrated northwards to the East African Coastal Current (EACC) area. As for May, 2020 the mapping of the $\mathrm{SST}_{\mathrm{A}}$ presented In Figure 2 (c) revealed that over the northern coastal Tanzania $\mathrm{SST}_{\mathrm{A}}$ was further reduce to a range of $-0.5^{\circ} \mathrm{C}$ to $0^{\circ} \mathrm{C}$ and that of EACC and Somali coast was reduced to range of 0.5 to $1.5^{\circ} \mathrm{C}$ indicating the cessation of MAM rainfalls, while that of the northeastern Madagascar at grid points defined by $2^{\circ}-10^{\circ} \mathrm{S}$ and $45^{\circ}-60^{\circ} \mathrm{E}$ was increased to range of $1.5^{\circ} \mathrm{C}$ to $2.5^{\circ} \mathrm{C}$. Moreover, Figures 2 (a)-(c) revealed that $\mathrm{SST}_{\mathrm{A}}$ variations from March to May, 2020 followed the direction of the surface winds (southeasterly flow) and then turn to be northeasterly to westerly, also this mapping have shown the influence of EACC circulation. Besides, the $\mathrm{SST}_{\mathrm{A}}$ over the northwestern cape of Madagascar remained at higher values throughout the season leading to moisture advection to NCT and Zanzibar. Also in Figure 2(c) the $\mathrm{SST}_{\mathrm{A}}$ values over northern coastal areas (particularly eastern Pemba) were 


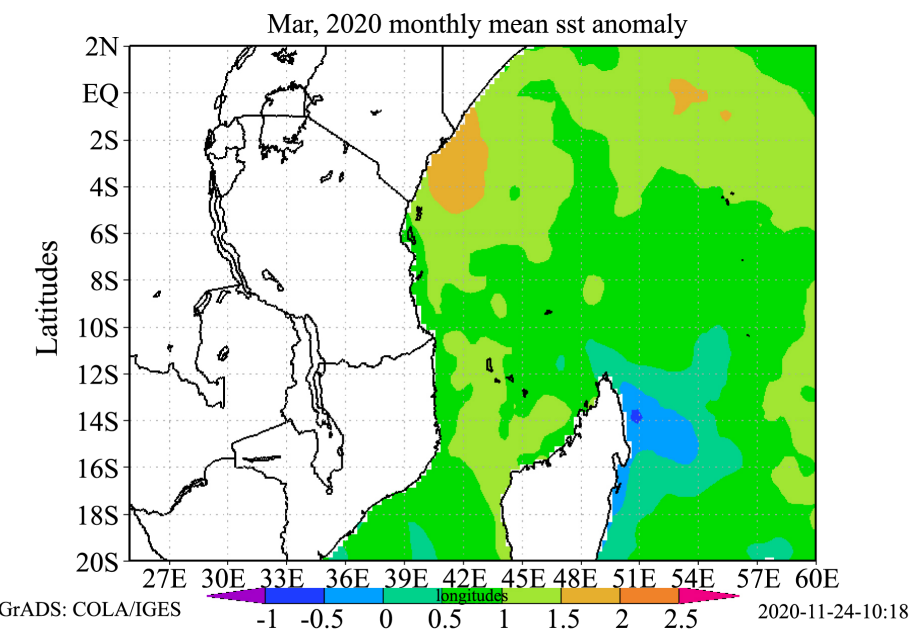

(a)
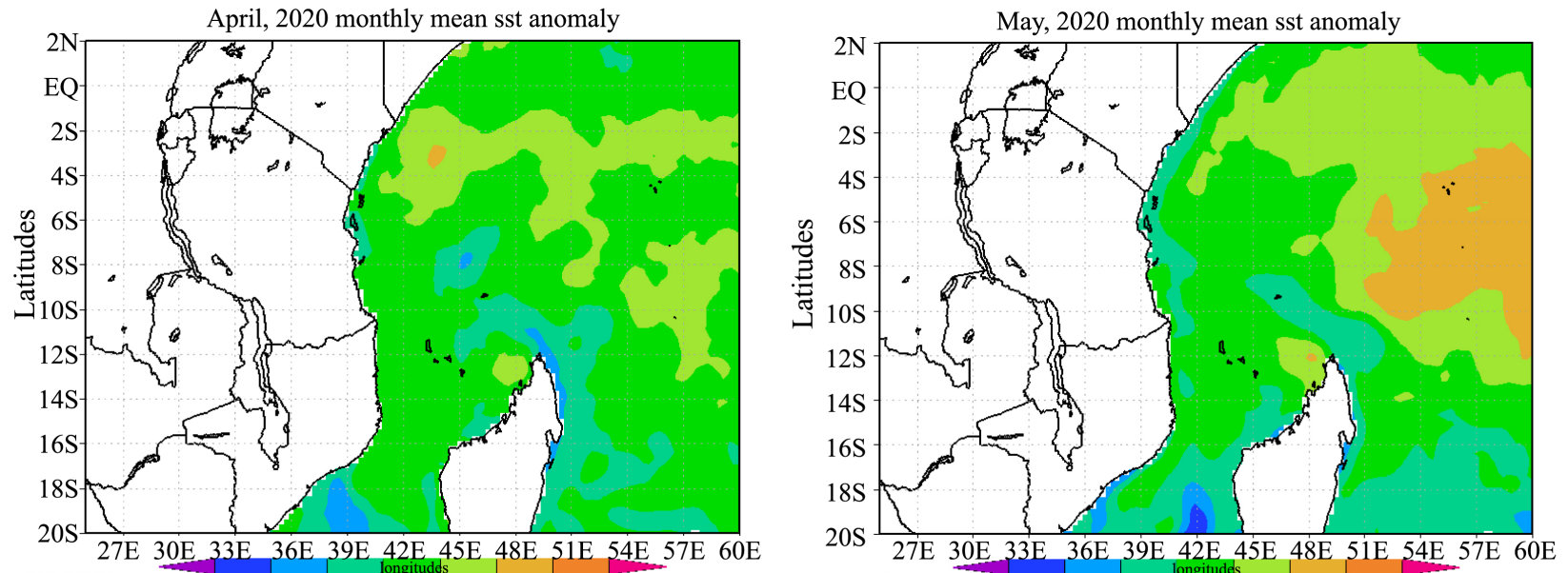

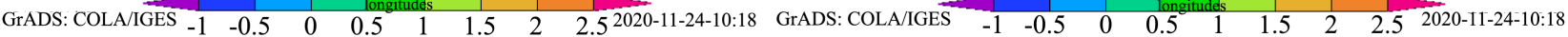

(b)

(c)

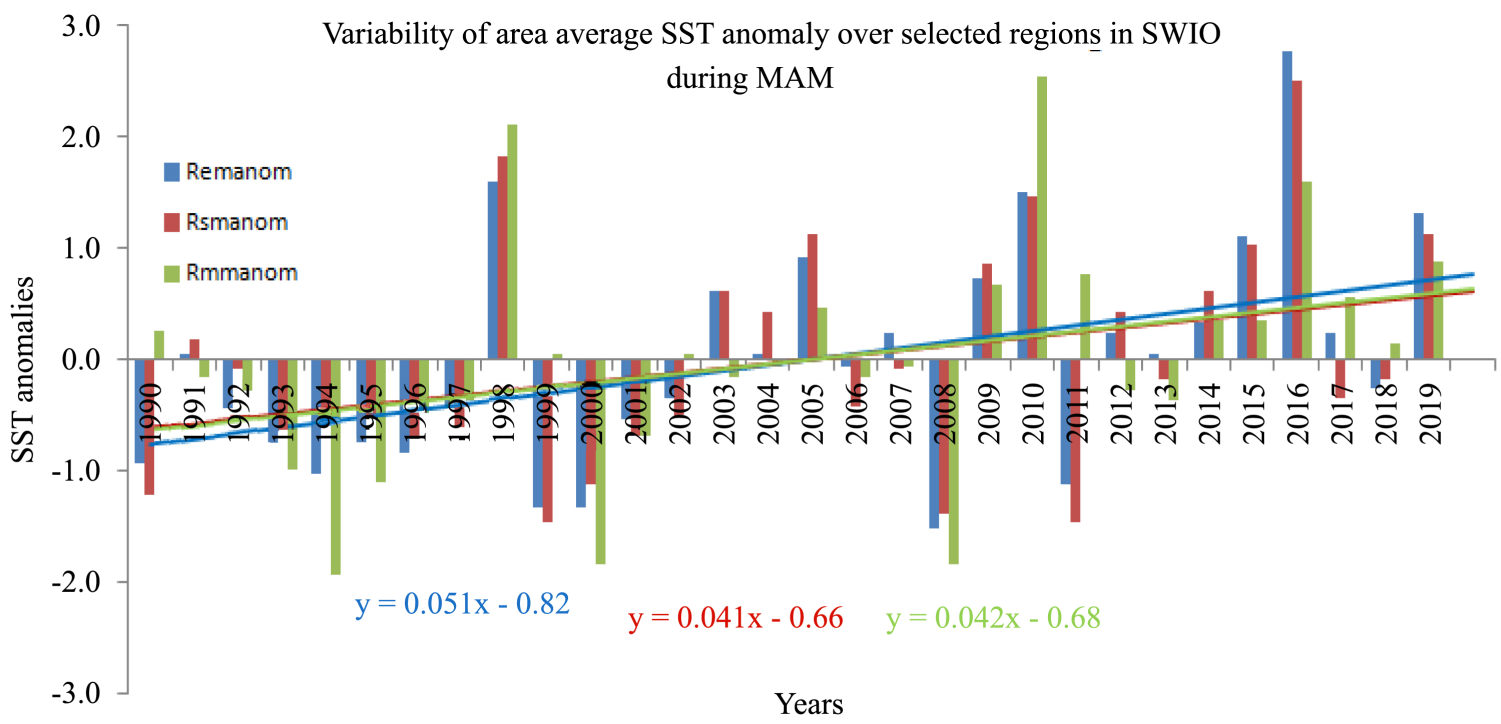

(d)

Figure 2. Variability of monthly mean $\mathrm{SST}_{\mathrm{A}}$ for April to May, 2020 as well as the area average $\mathrm{SST}_{\mathrm{A}}$ over selected areas $\mathrm{SWIO}$ during MAM seasons of 1990-2019. 
higher than that southern coastal areas (e.g., Unguja and Dare Salaam) leading to have more rainfall in Pemba during May than over Unguja.

Results of the area average $\mathrm{SST}_{\mathrm{A}}$ during the last 30 MAM periods (i.e. 1990-2019) over the selected regions in SWIO (i.e., Re, Rs, Rm) presented in Figure 2(d) shows that $\mathrm{MAM} \mathrm{SST}_{\mathrm{A}}$ over region Re is increasing at a faster $\left(0.05^{\circ} \mathrm{C} /\right.$ season $)$ rate than that of $\mathrm{Rs}$ and $\mathrm{Rm}\left(0.04^{\circ} \mathrm{C} /\right.$ season $)$. Moreover, results in Figure 2(d) reveals that with the exception of 1998 (strong El Nino year), the MAM seasons of 1990 to 2004 had dominated by relatively cooler $\mathrm{SST}_{\mathrm{A}}$ than that from 2005 to 2019 indicating that the second decade of the $21^{\text {st }}$ century (with the exception of 2008 and 2011) was dominated by increased warming over most regions in SWIO, the condition which enhances anomalous rainfall in most seasons. Also it could be explained that the low $\mathrm{SST}_{\mathrm{A}}$ during the warm period of 2005-2019 (Figure 2(d)) could be explained by the presence of the cold phases of El Nino (La Nina) events. As for the correlation between the long-term MAM seasonal rainfall over the selected areas in Zanzibar (Figure 1) and the long term (1990-2019) area average $\mathrm{SST}_{\mathrm{A}}$ during MAM over the oceanic regions Re, Rs and Rm revealed the area averaged $\mathrm{SST}_{\mathrm{A}}$ was poorly correlated with MAM rainfall anomalies at Karume airport Pemba, Kizimbani and Zanzibar airport in Unguja. The only significant correlation of $r=0.3(p \leq 0.1)$ was obtained between May $S T_{A}$ at $R m$ with MAM rainfall at airports of Karume and Zanzibar airport in Zanzibar. Otherwise all the monthly and seasonal correlation was either positively or negatively weak. This result indicates that southeasterly area averaged winds from $\mathrm{Rm}$ (Northern Madagascar) had significant impact to MAM rainfall in some stations of Zanzibar.

\subsection{Monthly Mean Wind Circulation at 850 and 700 Millibars (mb) during MAM 2020}

Results of moisture transporting agent during MAM 2020 at 850 and $700 \mathrm{mb}$ presented in Figure 3 shows that the wind circulation during March, 2020 over NCT and Zanzibar shows a weak northward flow at $850 \mathrm{mb}$ (black arrows) and a weak north eastward flow at $700 \mathrm{mb}$ (red arrows). The $850 \mathrm{mb}$ wind seemed to be parallel with the coast due to the influence of cyclonic circulation situated at northeast Madagascar the phenomenon which leads the $700 \mathrm{mb}$ wind to be linearly converged at the Dar es Salaam and Lindi areas with offshore orientation towards the cyclonic areas. Irrespective of the direction and orientation but in general the mean 850 and $700 \mathrm{mb}$ wind across coastal Tanzania and its coastal waters and hinterlands during March, 2020 were vey variable indicating atmospheric instability and moisture dumping effect. The cyclonic circulation along the northeastern Madagascar was not having high impact to Tanzania due to its orientation which resulted southerly flow along the coastal Tanzania and Zanzibar in particular. This could be among the reason, as to why March, 2020 rainfall was not as strong as that of April, 2020.

The spatial distribution of the mean 850 and $700 \mathrm{mb}$ wind circulation over the southwestern IO domain during April, 2020 presented in Figure 3(b) revealed 


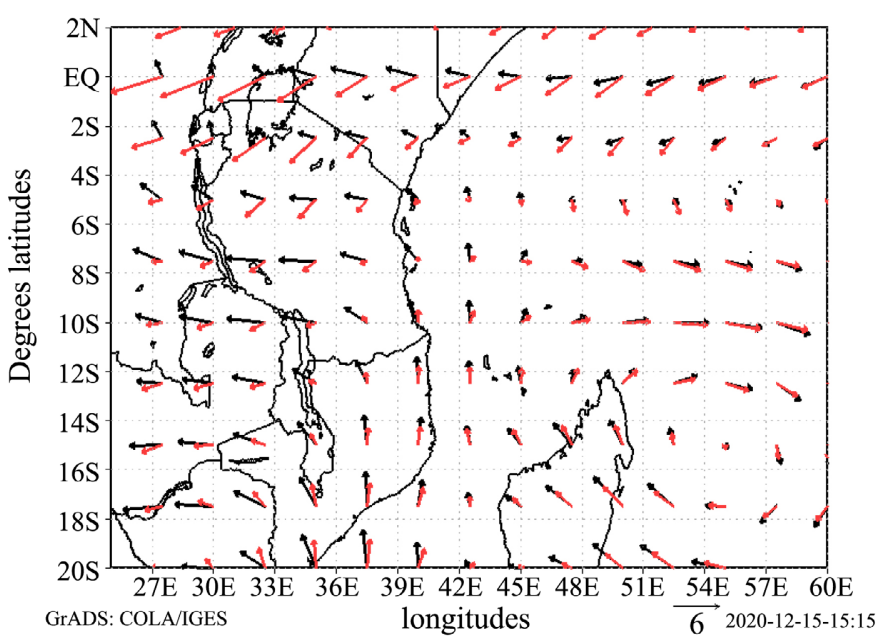

(a)

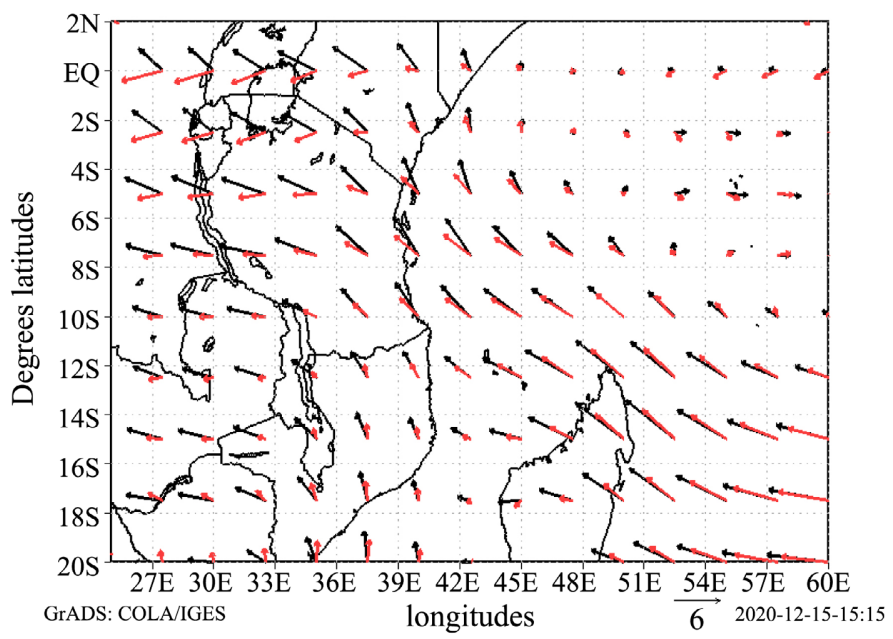

(b)

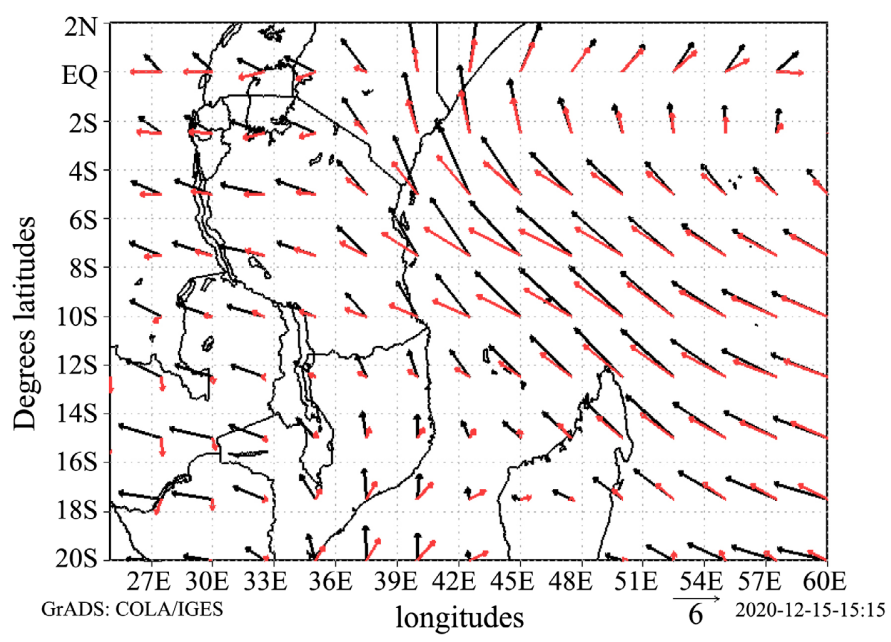

(c)

Figure 3. The $850 \mathrm{mb}$ (black) and $700 \mathrm{mb}$ (red) wind circulations during March to May, 2020 over the SWIO domain. (a) March 2020850 (black) and 700 (red) mb wind circulation; (b) April 2020850 (black) and 700 (red) mb wind circulation; (c) May 2020850 (black) and 700 (red) mb wind circulation. 
that the entire coastal strip of Tanzania was under the influence of long track southeasterly flow indicating a moisture deposition along the coast especially NCT (i.e., Dar, Zanzibar and Tanga). The cyclonic flow at further east of the coastal Tanzania (at about $2^{\circ}-8^{\circ} \mathrm{S}$ and $48^{\circ}-60^{\circ} \mathrm{E}$ ) could be among the sources of the strong moisture deposition over NCT which may lead to have high rainfall during April, 2020.

As for May, 2020 the spatial distribution of the wind circulation at 850 and $700 \mathrm{mb}$ for the SWIO domain shows that the northern coastal areas of Tanzania was dominated by strong southeasterly winds, but southern and Lake Victoria Zone was under the influence of weak circulation (Figure 3(c)). This indicates more moisture deposition at Lake Zone and southern regions than along the coastal regions. This also could be among the reason of having small May, 2020 rainfall over most stations in Unguja and Dar es Salaam as compared to northern stations of Pemba and Tanga).

\subsection{Monthly Mean PRW Variability during March to May, 2020}

The monthly distribution of PRW for MAM, 2020 presented in Figure 4 reveals that for the entire MAM 2020 period the coastal Tanzania (Zanzibar in particular) was under the influence of high amount of PRW ranged $30-50 \mathrm{~mm} / \mathrm{day}$, and this amount was deviating away from the coastal and pushed northeastward as we approaches May, 2020. For instance, on March, 2020 (Figure 3(a)) the entire coastal line of Tanzania was covered by a $30-50 \mathrm{~mm} /$ day PRW contour, while on April, 2020 (Figure 4(b)) the $30-50 \mathrm{~mm} /$ day PPW contour was shifted more eastward living some coastal highland and hinterland with little amount of PRW. As for May, 2020 (Figure 4(c)) further Ocean ward shift of the PRW was observed over the coastal line of Tanzania leaving the coast with less PRW of less than $39 \mathrm{~mm} /$ day, with Pemba having higher value ranged from $39-50 \mathrm{~mm} /$ day. This phenomenon of having more PRW in Pemba during May could be explained by the fact that the MAM (Masika) rainfall is more influenced by the southeasterly and easterly wind flow, resulting the moisture to be advected more in Unguja during March to April (due to the position of ITCZ as it shifts from south to north) and more in Pemba during May (where the ITCZ is positioned more northwards of $23^{\circ} \mathrm{S}$ ). Hence, leading Unguja to heave peak Masika rainfall during April, while Pemba to heavy downpour of Masika in May.

\subsection{Monthly Mean Relative Humidity Variability during March to May, 2020}

The spatial mapping of the Rhum for 850 and $700 \mathrm{mb}$ at the SWIO region for MAM, 2020 presented in Figure 5 reveals that, the $850 \mathrm{mb}$ the distribution of Rhum over the Tanzanian coastal strip Zanzibar being particular ranged from $50 \%-70 \%$ with higher moisture in the southern coast than in over the northern (Figure 4(a)). Similar results hold for April, 2020 (Figure 5(b)) but with more northward shift in higher moisture band and increased moisture in western areas of Unguja and Pemba Islands. As for May, 2020 Figure 5(c) revealed 


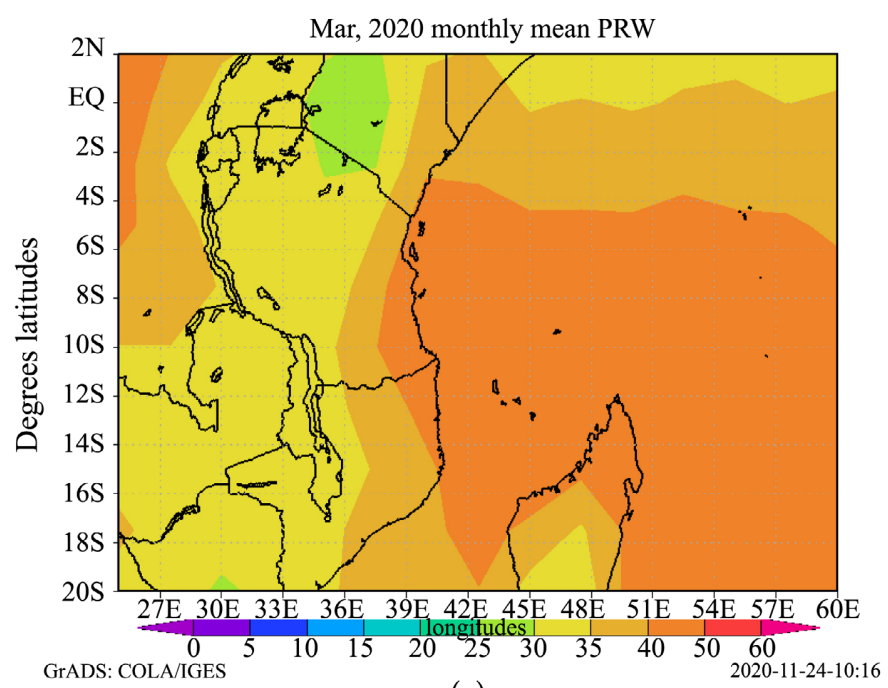

(a)

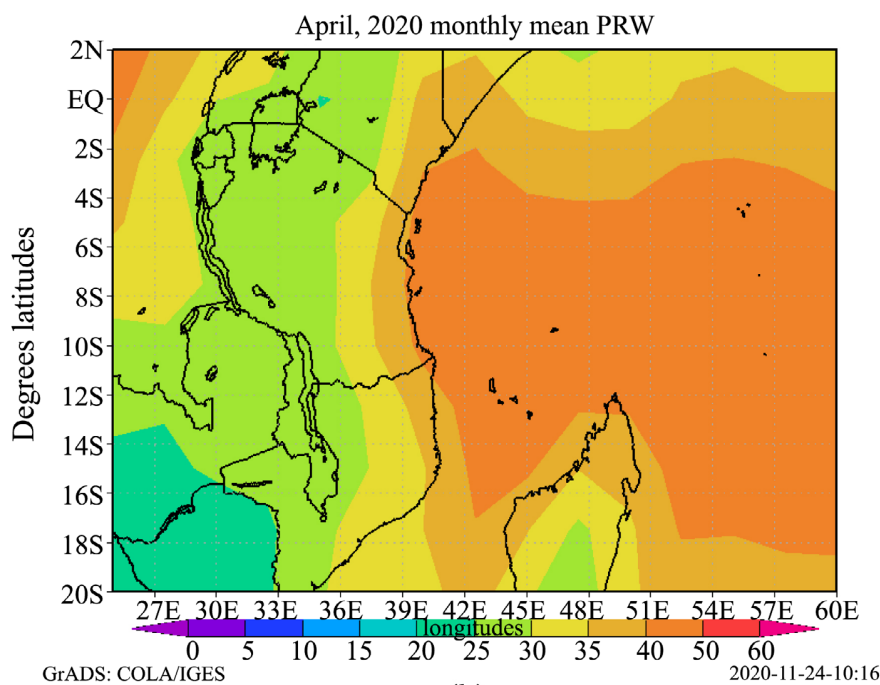

(b)

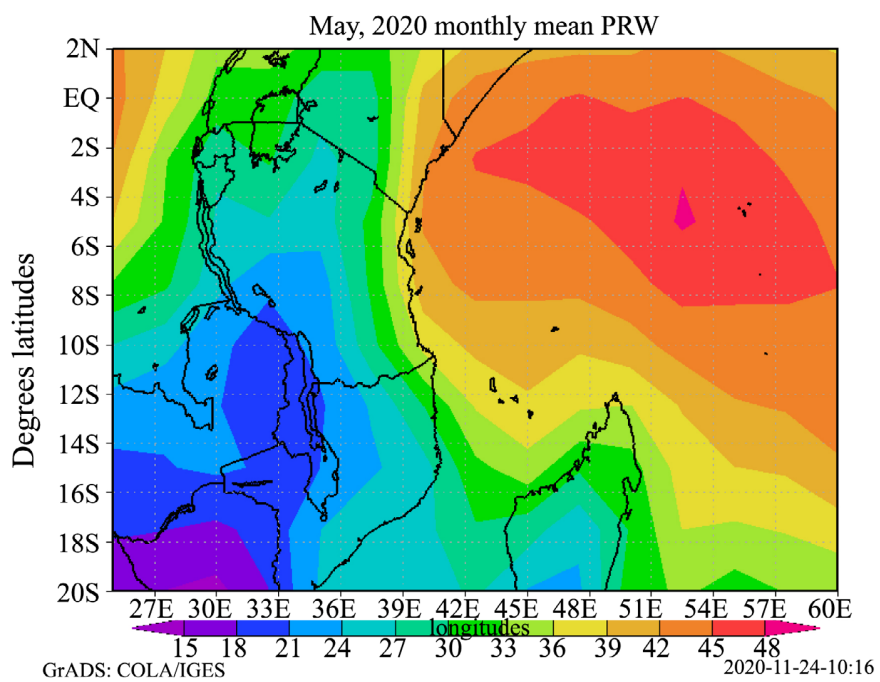

(c)

Figure 4. The monthly distribution of PRW at SWIO basin. Letters (a), (b) and (c) stands for March, April and May, respectively. 


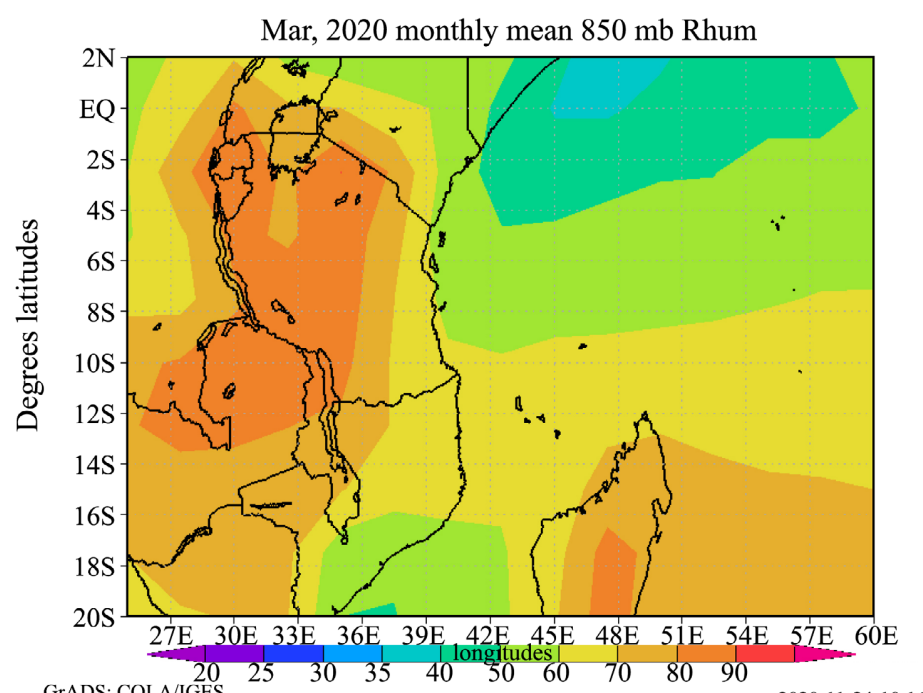

(a)

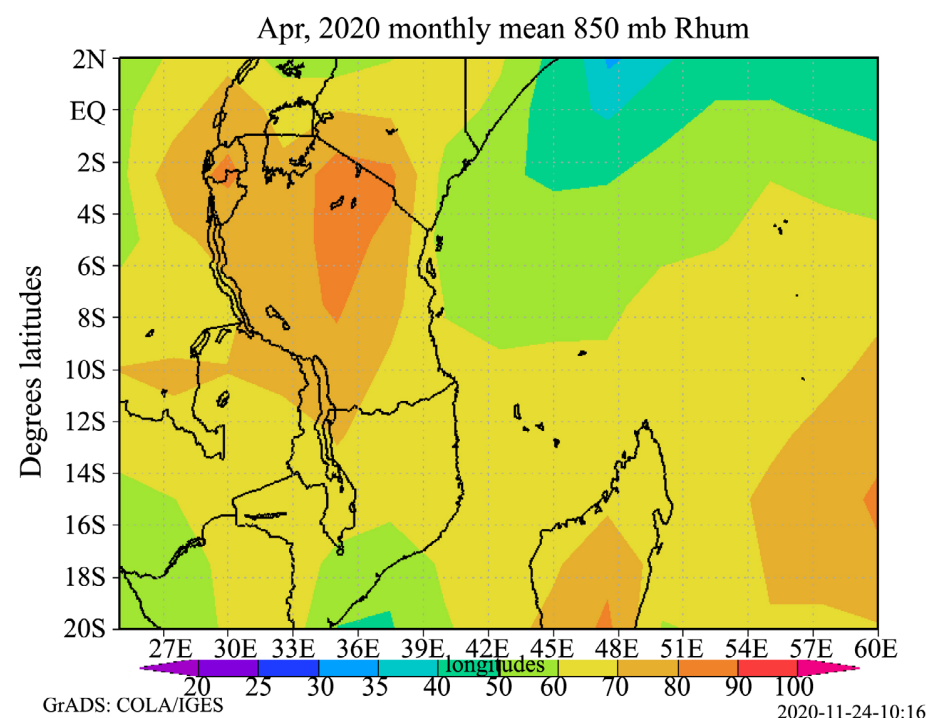

(b)

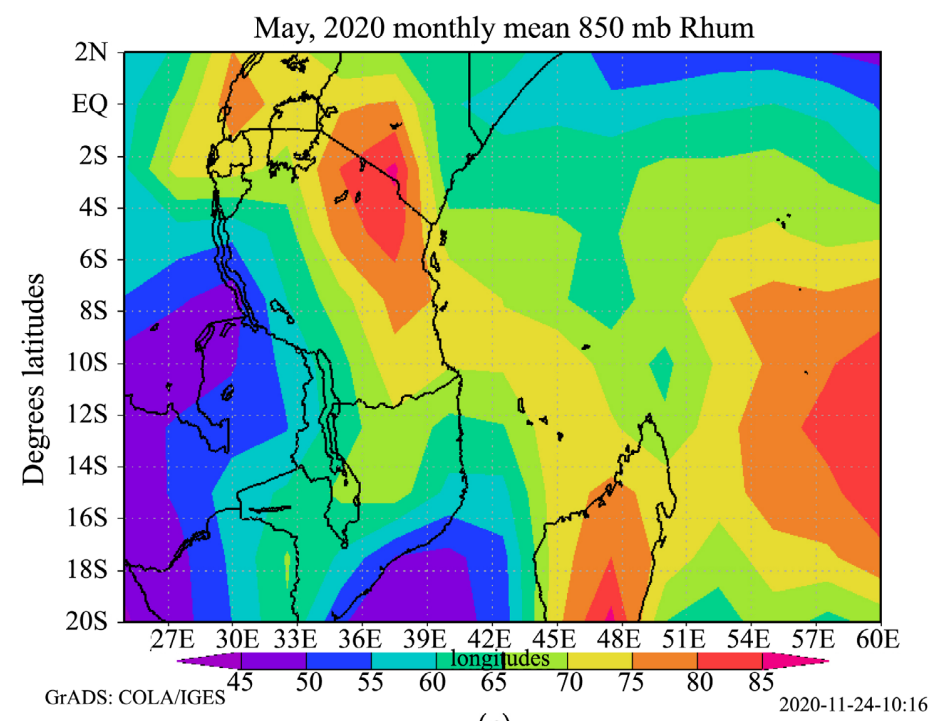

(c) 


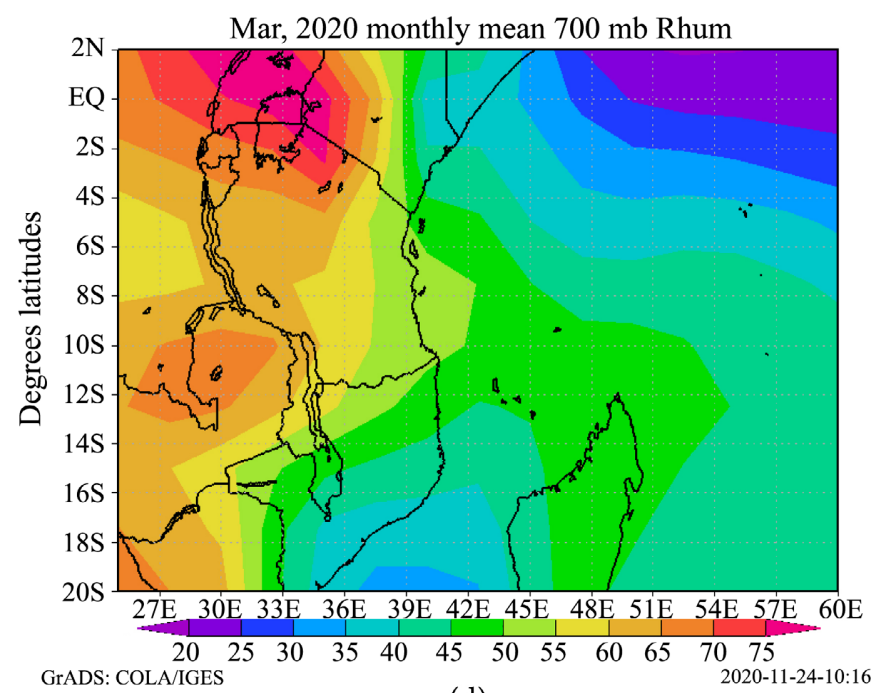

(d)

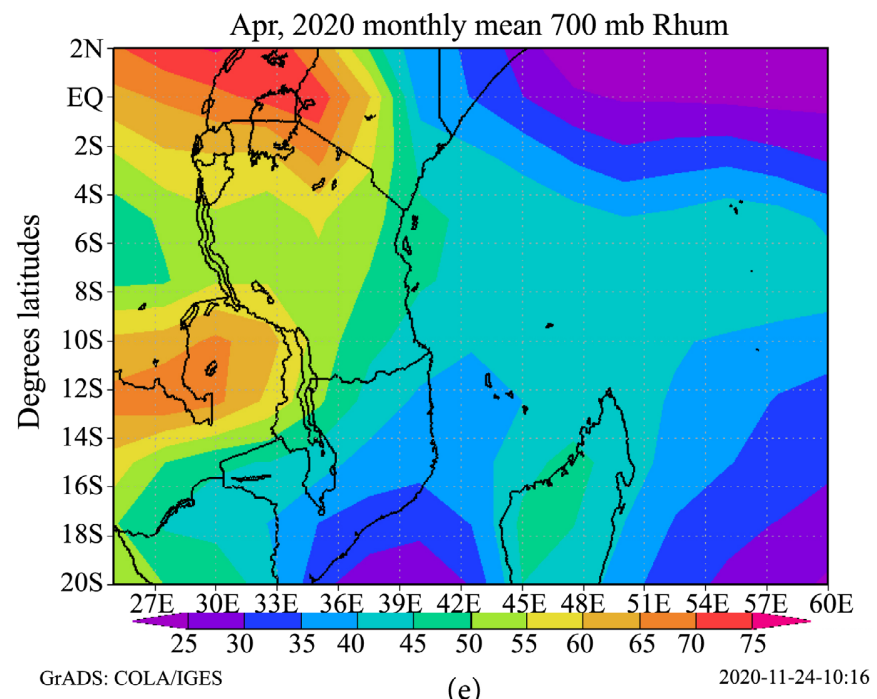

(e)

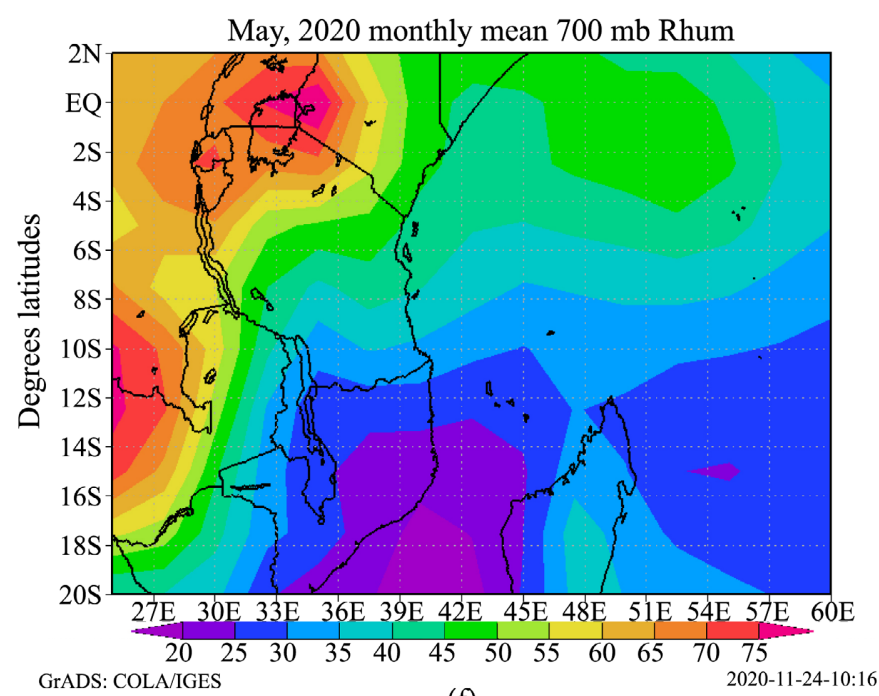

(f)

Figure 5. The 850 and $700 \mathrm{mb}$ moisture distribution during MAM, 2020 rainfall season over the SWIO region and Tanzania in particular. 
higher moisture band at northern coastal areas ranged from $70 \%-100 \%$ indicating the possibility of higher Masika rainfall during these period in areas of Kilimanjaro, Tanga, as well as Unguja and Pemba islands. Moreover, the moisture distribution for at $700 \mathrm{mb}$ results presented in Figure 5(d) and Figure 5(e) revealed declined moisture over the coastal areas as you go from March to May. For instance, higher moisture distribution at this level over Dar es Salaam, Zanzibar and Tanga was presented during March, 2020 (Figure 5(d)) while during April to May, 2020 the NCT areas including Unguja and Pemba had lower moisture content of at most 50\%, indicating: 1 ) less vertical extent clouds formation over NCT during MAM, 2020; and 2) the cessation of the Masika seasonal rainfall as mentioned earlier.

\subsection{Monthly Mean OLR Variability during March to May, 2020}

The results of the monthly mean variability of OLR for the SWIO region during Match to May, 2020 presented in Figure 6 reveals that, during March the coastal Tanzania was having low ORL values ranged from $230-240 \mathrm{~W} / \mathrm{m}^{2}$. However, the western Tanzania and northern Madagascar were having deep OLR values (less than $200 \mathrm{~W} / \mathrm{m}^{2}$ ) indicating more convective activities associated with deep clouds over these areas. As for April, 2020 the spatial distribution of OLR presented in Figure 6(b) reveal that NCT (including Zanzibar), northeastern highland and northwestern Tanzania had deep OLR values ranged from $200-230$ $\mathrm{W} / \mathrm{m}^{2}$ with the lowest OLR being mapped at Pemba island. The results in Figure 5 (b) indicates that deep convective activities are located at northern coast (Dar, Zanzibar and Tanga) as well as the northwestern areas including Rwanda and Burundi, resulting into heavy rainfall over these areas. Lastly, the OLR distribution for May, 2020 (Figure 6(c)) revealed that only area over the coastal Tanzania which has deep convection was Pemba and extreme northern Tanga areas, these areas had deep convection OLR of $240-250 \mathrm{~W} / \mathrm{m}^{2}$. The results from Figures $6(\mathrm{a})-(\mathrm{c})$ indicates a northward shifting of the convective activities from south due northward propagation of the Inter Tropical Convergence Zone (ITCZ). As mentioned earlier this northward propagation of ITCZ could be among the main reasons as why the peak Masika rainfall in northern coastal areas including Pemba and Tanga is during May while in areas of Dar es Salaam at Unguja the peak is on April.

\subsection{Ocean Thermal Energy during MAM, 2020 Rainfall in Zanzibar}

The net heat flux into the ocean is a sum of different heat exchange processes at ocean surface, including heating due to Short-Wave Radiation (SWR), Net outgoing Long-Wave Radiation (NLWR), Sensible Heat Flux (SHF), and Latent Heat Flux (LHF). The SWR contributes to heat gain of ocean, NLWR and LHF lead to heat loss. The latent heat loss i.e. the heat required for the evaporation of surface water depend on SST, air humidity, and surface winds. This heat loss is the major contributor to oceanic heat loss, followed by radiative cooling due to net 


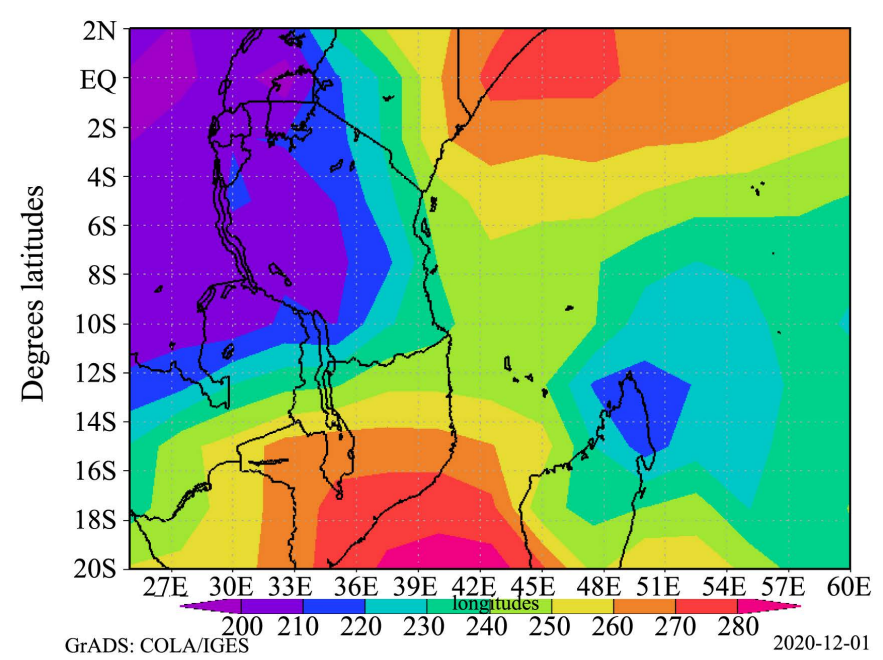

(a)

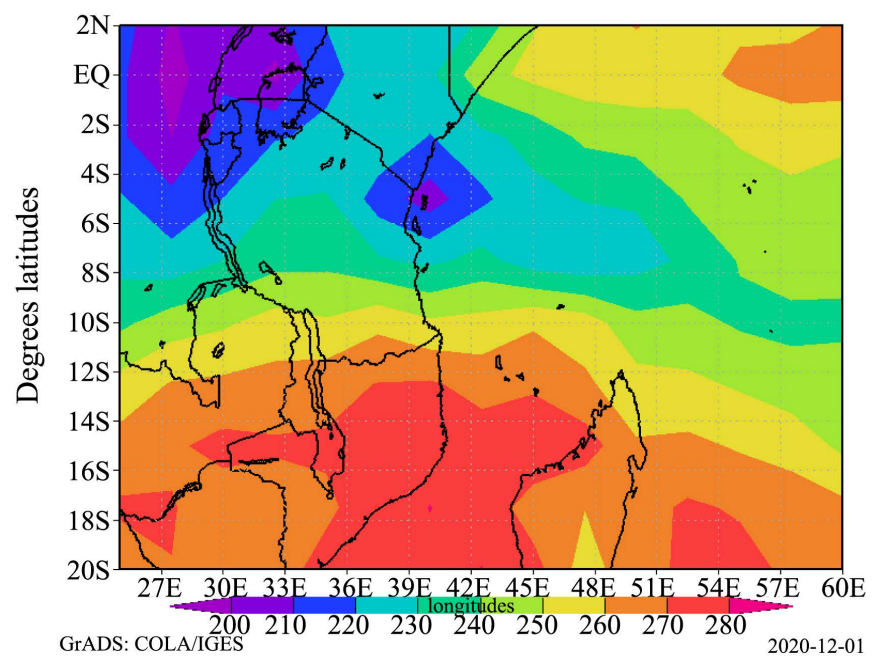

(b)

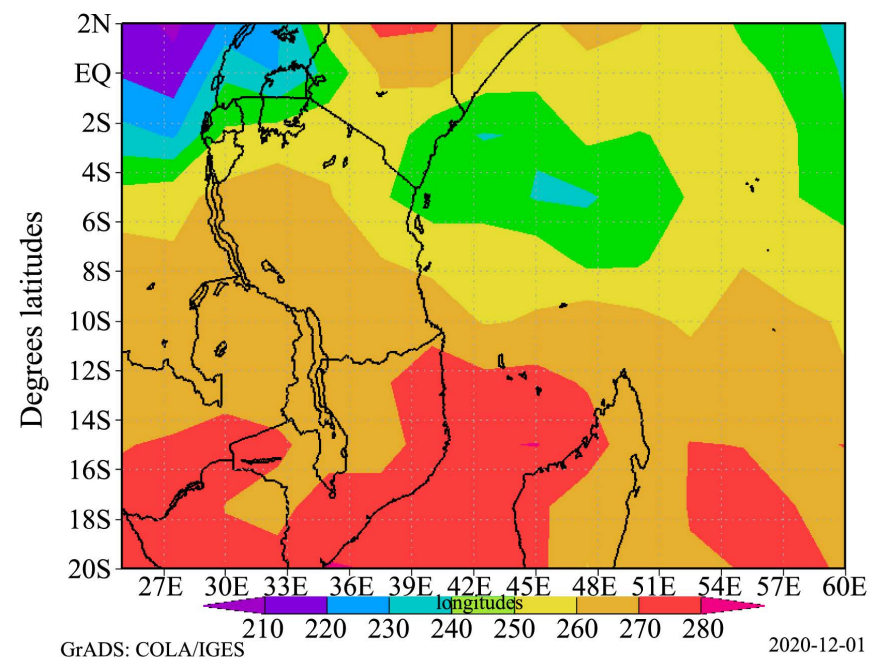

(c)

Figure 6. Spatial distribution of OLR during the MAM, 2020 seasonal rainfall. (a) The Mar 2020 mean OLR; (b) April 2020 mean OLR; (c) May 2020 mean OLR. 
outgoing long wave radiation [24]. In view of the above description, the results of the ocean net heat flux (which is responsible for evaporation) for the SWIO region for the three months of Masika (MAM), are presented in Figure 7. Results in Figure 7 reveals the highest ocean net heat flux over the coastal Tanzania ranged from $110-140 \mathrm{~W} / \mathrm{m}^{2}$ was mapped at the northern coastal areas and the southern Zanzibar channel, with northern Unguja mapped with the highest (Figure 7(a)). As for April, 2020 (Figure 7(b)) the highest net flux was pushed northward to the Somali coast leaving coastal Tanzania with very low net flux of about $0-40 \mathrm{~W} / \mathrm{m}^{2}$. Indeed, Figure 7(b) shows that Mozambican channel and East African Coastal Current (EACC) was under the influence of $50-70 \mathrm{~W} / \mathrm{m}^{2}$ indicating reduced evaporation due to decreased ocean warmth. As for May, 2020 the distribution of higher net ocean heat flux shows a further northward propagation with high values at the Somali coast and very low values (i.e., less 40 $\mathrm{W} / \mathrm{m}^{2}$ ) at the SWIO basin. These low values in net ocean heat flux from April to May, 2020 indicate an increased SST over the coastal areas as supported by [24] that SST warming along with the surface wind changes resulted in negative heat flux tendencies.

\subsection{March to May and MAM, 2020 Rainfall Strength in NCT and Zanzibar}

The results of the MAM, 2020 rainfall analysis over most stations in Zanzibar and NCT presented in Figure 8 reveal that, monthly spatial distribution of rainfall for the March to May, 2020 rains (Figure 8(a)), had March, 2020 rainfall of $\geq 100$ $\mathrm{mm}$ over all stations in Zanzibar. The highest rainfall of about $400 \mathrm{~mm}$ recorded in Kilombero and Mkoani (Zanzibar). As for April, 2020, Figure 8(a) reveals that most stations had rainfall ranged from $560 \mathrm{~mm}$ at Matangatuani to 1070 $\mathrm{mm}$ at Kizimbani agromet station. This phenomenon could be attributed by the fact that, MAM rainfall is more dominated by southeasterly to southwesterly and sometimes easterly winds (based on ITCZ immigration), and based on geographical set up of the two Island of Zanzibar (Figure 1), Unguja is firstly affected by the influence of these wind followed by Pemba, hence resulting the MAM rainfall to have its peak first in Unguja and then in Pemba. This argument is highly supported by results of spatial rainfall distribution during May, 2020 (Figure 8(a)) which shows that most stations in Unguja had low rainfall of at most 200 $\mathrm{mm}$, while stations in Pemba had higher rainfall ranged from $310-710 \mathrm{~mm}$. In addition to wind regimes during MAM period, also the northward shifting of the Inter Tropical Convergence Zone (ITCZ) could be another factor which influences the aforementioned argument. The spatial distribution of the MAM, 2020 rainfall over the eleven stations of Zanzibar presented in Figure 8(a) shows the highest rainfall over all stations. This rainfall ranged from $1014 \mathrm{~mm}$ (Victoria garden Unguja) to $2100 \mathrm{~mm}$ (Mkoani Pemba). Also Figure 8(a) shows that the MAM 2020 rainfall was abundant and spatially well spread across Zanzibar, with the highest record over the stations resident along the western side of the islands than those along the eastern. The strength of percentage 


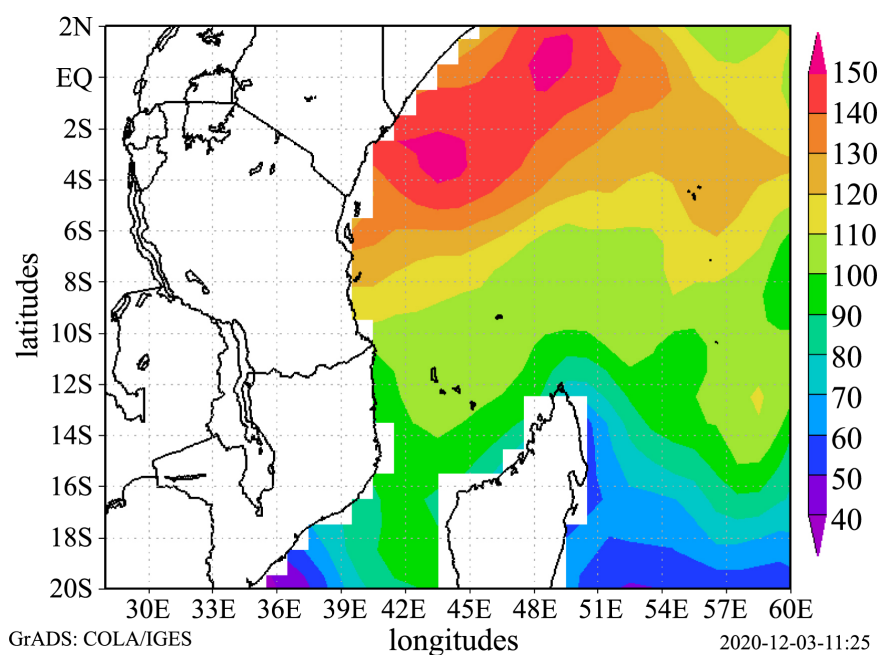

(a)

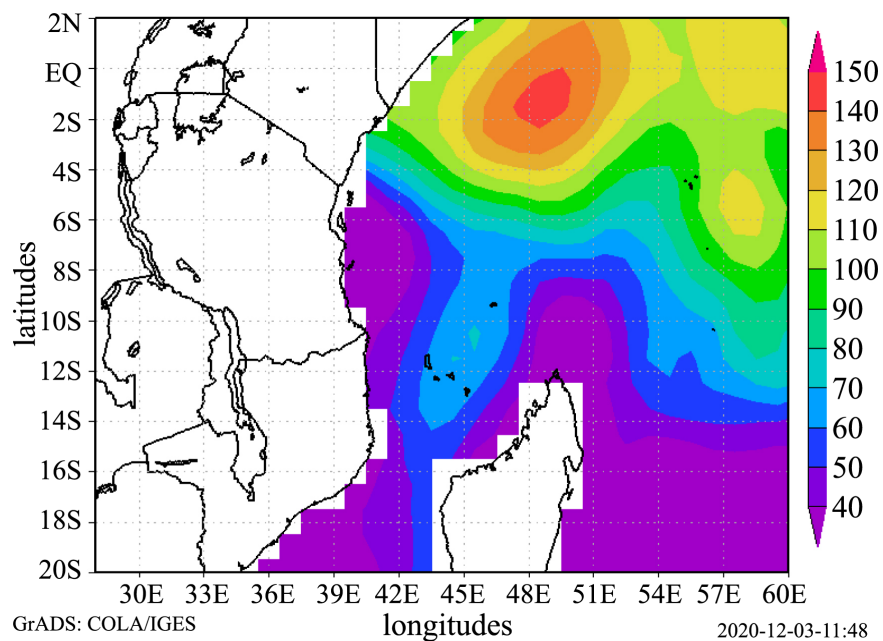

(b)

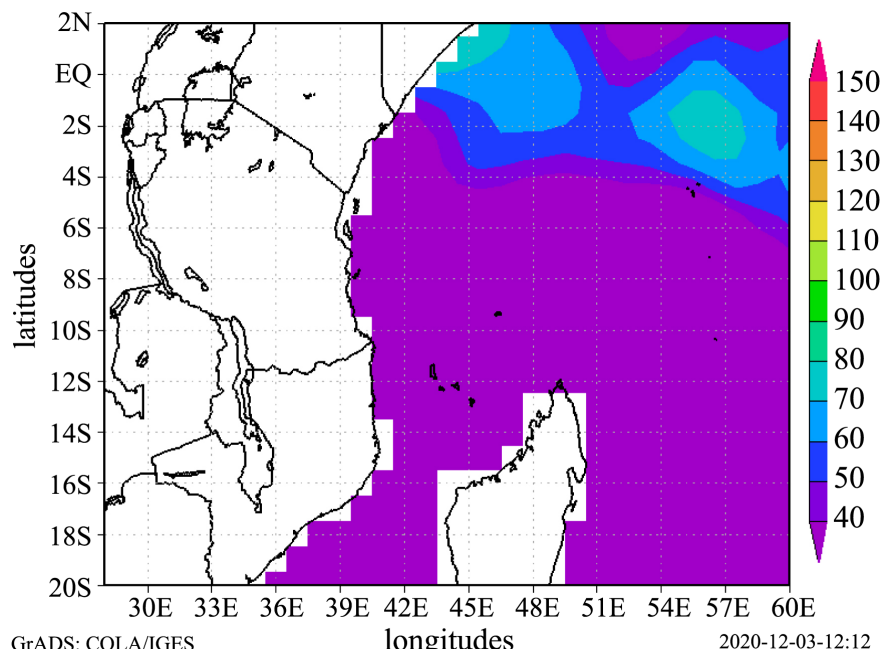

(c)

Figure 7. The distribution of the oceans net heat flux during March to May, 2020. (a) March 2020 ocean heat flux $\left(\mathrm{W} / \mathrm{m}^{2}\right)$; (b) April 2020 ocean heat flux $\left(\mathrm{W} / \mathrm{m}^{2}\right)$; (c) May 2020 ocean heat flux $\left(\mathrm{W} / \mathrm{m}^{2}\right)$. 


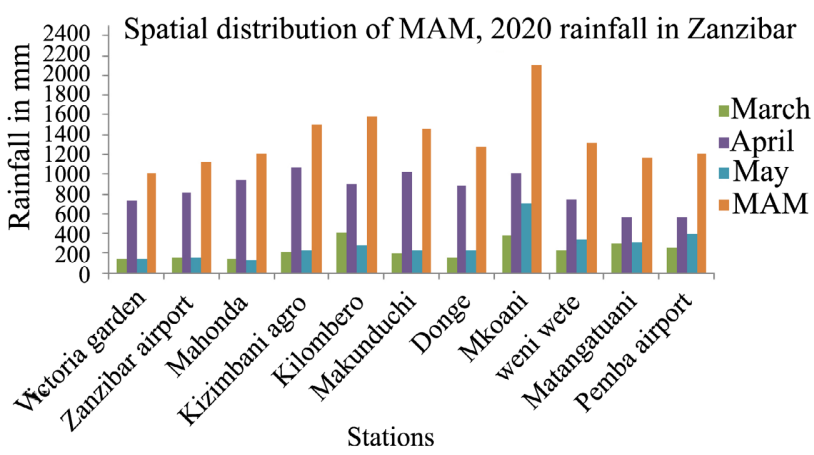

(a)

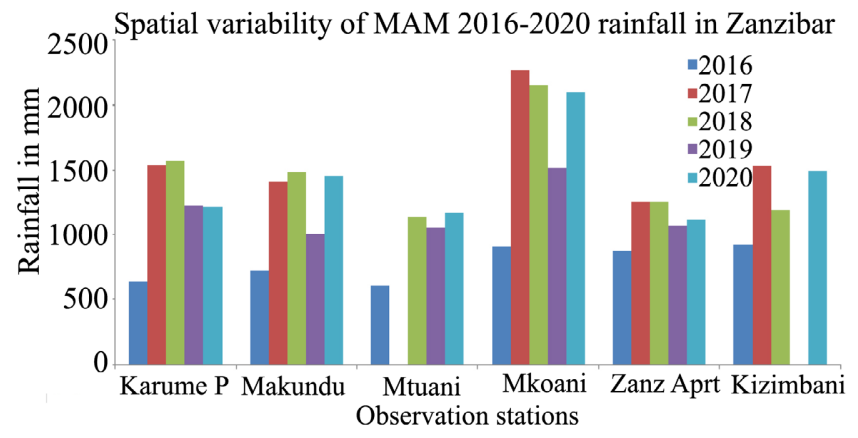

(c)

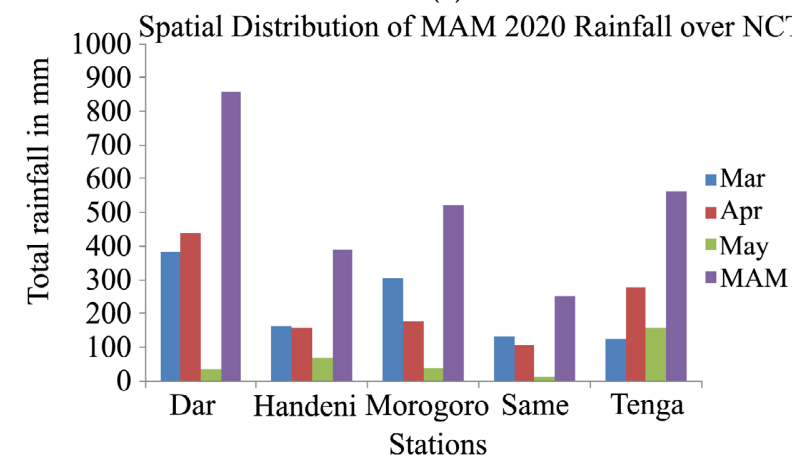

(e)

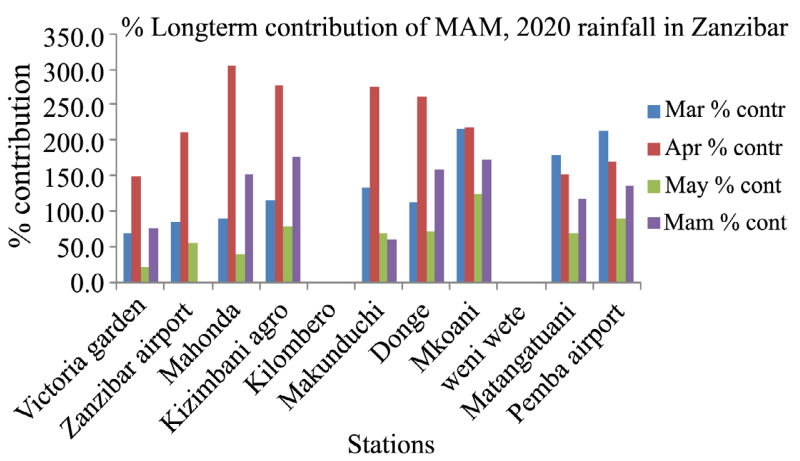

(b)

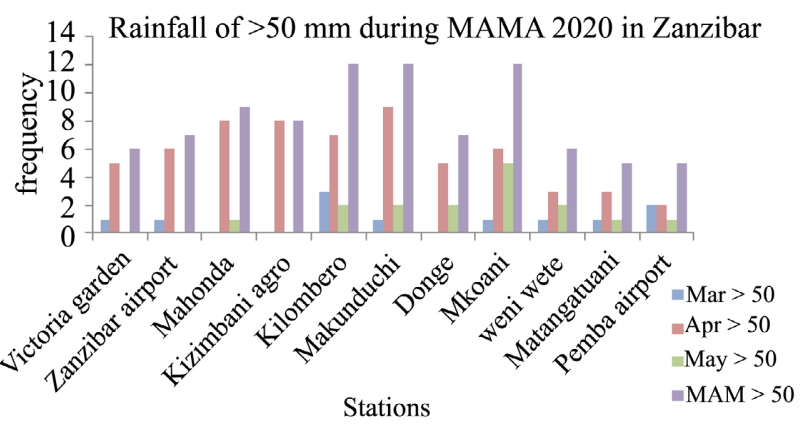

(d)

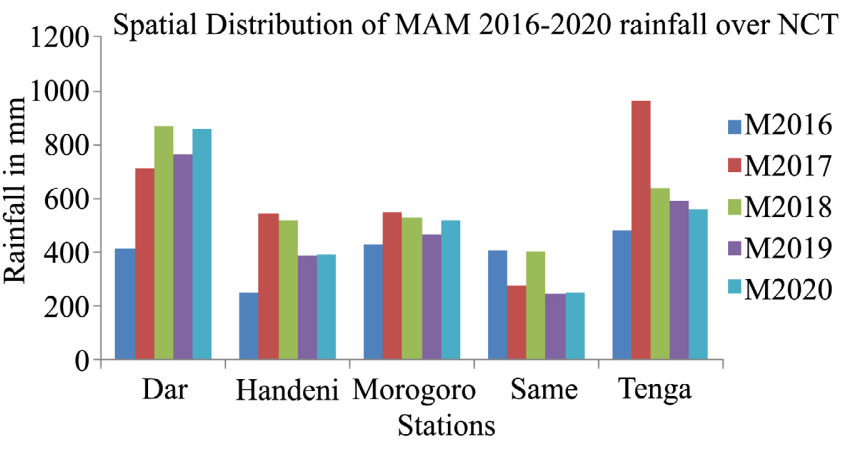

(f)

Figure 8. (a) The spatial rainfall distribution of MAM, 2020 (Zanzibar); (b) The percentage long-term distribution of the MAM 2020 rainfall in Zanzibar; (c) The MAM rainfall for the five consecutive MAM seasons of 2016, 2017, 20189019 and 2020 (d) The frequency of $>50 \mathrm{~mm}$ recorded at various station in Zanzibar during MAM, 2020; (e) Spatial distribution of MAM rainfall over NCT; (f) Spatial distribution of MAM rainfall for the five consecutive (2016-2020) years over NCT.

contribution of March to May, 2020 rainfall based on monthly and seasonal long term mean (Figure 8(b)) shows that March and April 2000 has higher contribution compared to May 2020. For instance, March, 2020 had a higher percentage contribution of greater than 200\% at Mkoani and Karume airport (Pemba), while the percentage contribution for March, 2020 ranges from 50\% - 150\% in many stations at Unguja. As for April, 2020 results revealed that the highest percentage contribution of more than $300 \%$ of the long term mean was at Mahonda, whereas Donge, Makunduchi, Kizimbani agro meteorological station and Zanzibar airport had higher contribution of about 250\% - 280\%, while Mkoani, Matangatuani and Karume airport had a contribution ranged from 150\% - 200\%. As in the monthly totals, the percentage contribution of the May, 2020 rainfall to 
the long term mean is higher in Pemba than at Unguja stations. The results in Figure 8(b) show that Mkoani and Karume airport had percentage contributions of $173 \%$ and $135 \%$, whereas other remaining stations had lower percentage contributions of less than $160 \%$ to the long term. The MAM, 2020 rainfall over most station in Zanzibar had higher percentage contribution as compared to the long-term mean of the MAM rainfall. Moreover, results in Figure 8(b) reveal that stations in Unguja had higher percentage contribution than that of Pemba. For instance, Mahonda, Kizimbani, Donge (Unguja) had percentage contributions ranged from 100\% - 180\% while Mkoani, Karume airport and Matangatuani (all in Pemba) had percentage contributions ranged from $150 \%-200 \%$, indicating that usually Pemba had higher range of MAM rainfall than in Unguja.

The results in Figure 8(c) show the strength of the five consecutive MAM rainfalls seasons in most stations of Zanzibar (Unguja and Pemba). Figure 8(c) revealed that all listed years had higher MAM rainfall of greater than $500 \mathrm{~mm}$, with 2017 and 2020 being the leading in this record. For instance, MAM, 2017, 2018 and 2020 had highest rainfall of more than $2100 \mathrm{~mm}$ at Mkoani and Karume airport (in Pemba), Makunduchi and Kizimbani agro meteorological station (in Unguja) had 2017 to 2020 MAM rainfall of more than $1500 \mathrm{~mm}$, while the remaining stations (i.e., Matangatuani and Zanzibar airport had MAM rainfall ranged from $1000-1500 \mathrm{~mm}$. The MAM rainfall of 2016 and 2019 were also higher than the previous long term records but was at lower scale compared to 2017, 2018 and 2020 MAM rainfalls in Zanzibar. The monthly and seasonal rainfall spatial distribution for the NCT areas (Dar es Salaam, Morogoro, Handeni, Tanga and Same) presented in Figure 8(e) show that Dar es Salaam, Tanga and Morogoro had higher MAM 2020 rainfall ranged from $560-860 \mathrm{~mm}$, while Handeni and Tanga had relative lower rainfall $(250-430 \mathrm{~mm})$. As for the monthly distribution Figure 8(e) show that Dar es Salaam and Tanga had higher (270 $380 \mathrm{~mm}$ ) rainfall in April, while Dar and Mororgoro had rainfall ranged from 306 - 383 mm; further results in Figure 8(e) revealed that May, 2020 had very low rainfall over all NCT stations, with the lowest $(11.5 \mathrm{~mm})$ in Same.

Indeed, the results of the severity of the MAM 2020 rainfall for most Zanzibar stations, Figure 8(d) reveal that Kilombero, Makunduchi and Mkoani had higher frequency (12 days) of severe rainfall during the MAM, 2020 rainfall season. Moreover, Figure 8(d) show that most stations in Unguja had higher frequency of severe rainfall index $(50 \mathrm{~mm} /$ day $)$ than stations in Pemba. As for the severity index of March to May rainfall in NCT results shows a total frequency of 10 events in March and April with no event in May, and out of these events, 6 occurred in Dar es Salaam and 2 in Tanga. Our results are in agreement with [18] who noted that MAM rainfalls had significant contribution of the amount of heavy rainfall also our study findings are in agreement with [3] who noted a high rainfall contribution (30\% - 60\%) during MAM periods. Further results indicate that over Zanzibar, April, 2020 rainfall had higher frequency of severe rainfall index than March and May, 2020 with stations in Unguja having higher frequency than that of Pemba. Indeed, results show that Mkoani had higher fre- 
quency (4 days) of severe rainfall index during May, 2020 than any station in Zanzibar. Besides, results revealed that during May, 2020 most station in Pemba had received a severe rainfall index with frequency ranged from 1 - 4 events per month, but only four stations (Mahonda Kilombero Donge and Makunduchi) in Unguja had a received an event which qualify to the severe rainfall index. Also these results indicate that more societal impacts could be registered in Unguja during April, 2020 and in Pemba during May, 2020. As for the total number of severe rainfall index per month over all investigated rainfall stations in Zanzibar results revealed that a total of 89 severe rainfall events were recorded from March to May, 2020.The distribution of these events shows that 11 events occurred in March, 62 events during April and 16 during May, 2020. The distribution between island shows that Unguja had a total of 61 events with 6 in March, 48 in April and 7 in May, while Pemba had 28 events of which its occurrence is 5, 14, and 9 for March, April and May 2020, respectively.

As for specific months (March, April and May) during various MAM rainfall seasons in Zanzibar results shows that on May, 2015, April, 2016, April, 2017, and April, 2020, Unguja had recorded high rainfall records which results in floods. For instance, during these stated dates TMA offices in airport Zanzibar had recorded a rainfall of 172, 212.4, 205 and $202.6 \mathrm{~mm}$, respectively. As for Pemba the same period of May, 2015, April, 2016, May, 2017 and April, 2020 TMA offices in Pemba had recoded heavy rainfall records of 74.2, 98.3, 164.5 and $124.2 \mathrm{~mm}$, respectively. The spatial and temporal rainfall distribution during the five consecutive MAM season (2016-2020) at the NCT presented in Figure 8(c) reveals that like in Figure 8(c) MAM rainfall during 2017 had highest rainfall in Tanga and Dar es Salaam, followed by Morogoro and Handeni with the least at Same region. The MAM periods of 2018 and 2020 had nearly the similar strengths in all stations with highest downpour at Dar es Salaam and Tanga, while the least recorded rainfall was at the same. Indeed, Figure 8(f) shows that for all five MAMs periods, same rainfall station had very low rainfall of at most $400 \mathrm{~mm}$. In comparison with the previous MAM seasonal rainfall, the 2020 MAM over most stations (at Zanzibar and NCT) has been very strong resulting to destructive events including flooding, land sliding, etc. This is due to the higher rainfall records during MAM 2020, as well as the consecutive two rainfall seasons of 2019 OND, DJF (2019-2020) which resulted the earth surface to be more saturated to absorb the heavy downpour of MAM, 2020.

\subsection{Socio Economic Implications of the MAM, 2020 Rainfall in Zanzibar and NCT}

The socio-economic implication of MAM, 2020 rainfall in Zanzibar as per DMC analyzed data (Figure 9) reveals great level of socio economic damages on both islands. For instance, Figure 9 shows some living houses were broken out and some houses were watered (filled with water, forcing the households to leave). The spatial distribution of the broken houses over Zanzibar (presented in Figure 9 (blue color)) revealed that Pemba districts had higher number of broken 


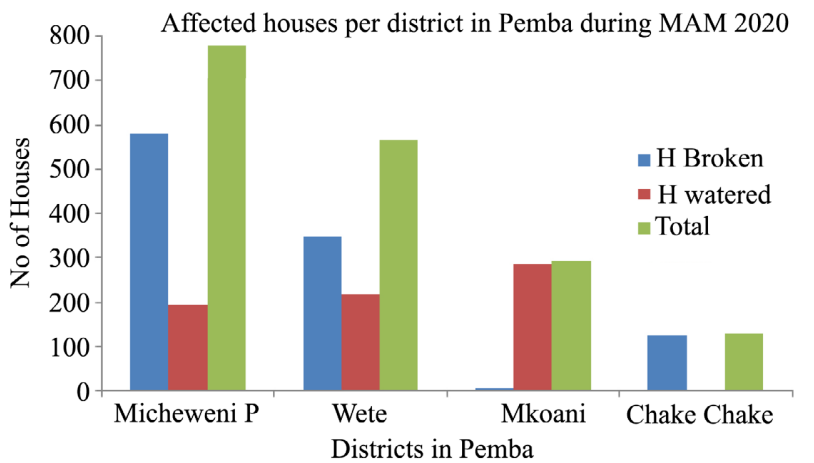

(a)

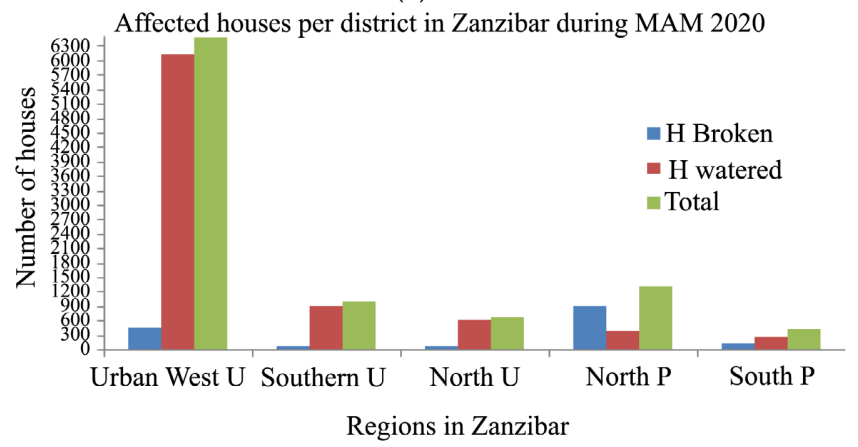

(c)

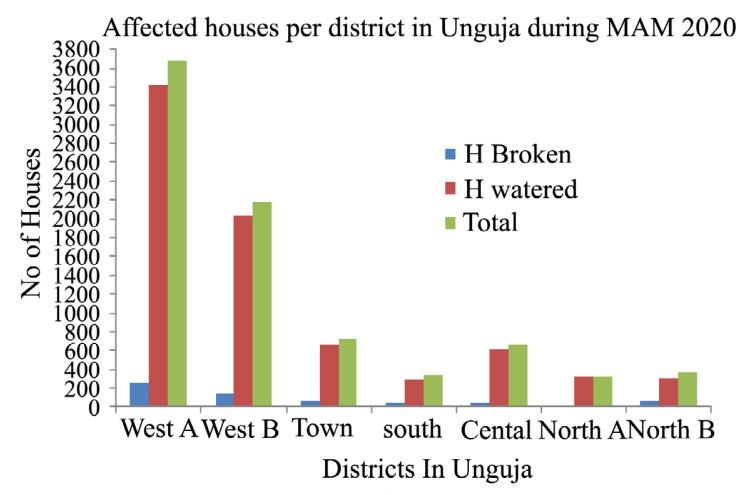

(b)

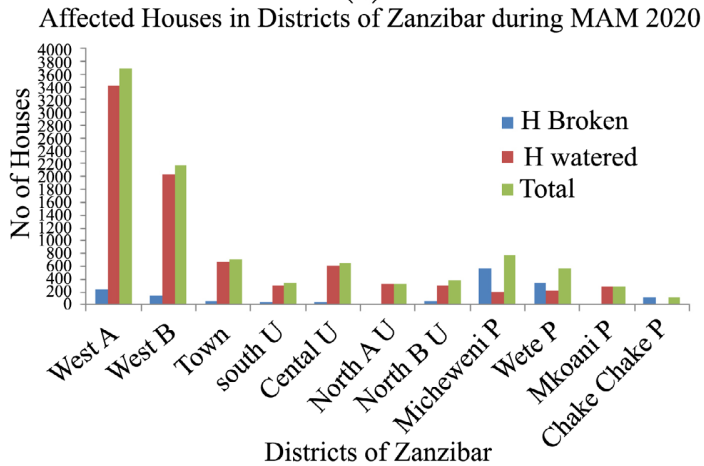

(d)

Figure 9. Damages of the May, 2020 rainfall in Zanzibar (source: Disaster Management Commission of the RGoZ).

housed compared to Ungua district. For instance, Micheweni, Wete and ChakeChake districts in Pemba had the highest number of broken houses (150 - 550) associated with the MAM 2020 rainfall compared to Unguja districts which had the highest record 210 houses in West A district. This could be attributed by the fact that Micheweni district in Pemba have weak housing structures and the area is very open (with no tree) hence strong wind and heavy rainfall could have more impacts. As for watered houses Figure 9 shows that Unguja districts have been more affected than districts in Pemba, the phenomenon which could be explained by the nature or geographical formation of the two islands, that Unguja is more flat and Pemba has more valleys and trough of small hills. For instance, West A have about 3400 watered houses (Figure 9(b)), followed by West B which had about 2000 watered houses. As for districts in Pemba the numbers of watered houses were higher at Micheweni District followed by Mkoani. As for the distribution of the total impacts (watered plus damaged) in regional perspectives results in Figure 9 revealed that the highest total impacts was in the Urban West region followed by North Pemba region. As for the districts distribution of the broken and watered houses results in Figure 9 reveals that West A and West B districts had more impacts (watered and broken houses) followed by Micheweni, Wete and Mkoani, respectively.

Other impacts associated with MAM, 2020 seasonal rainfall includes flooding, strong winds, irruption of the venereal diseases among others. In turn, these flooding and strong winds affected the infrastructure business, yields among others. 
Villages or wards including Ubago, Dunga, Bambi, Mgeni Haji, Kidimni, Chuini, Kihinani, Fuoni Uwandani, Kinyasini, Maziwani, Pembeni, Wingwi Njuguni, Sizini, Chimba, Mihogoni, Shumba Viamboni, Wingwi Mapofu and Mwambe, were severely affected.

Some few cases of destructions brought these MAM, 2020 rainfall are presented in Figure 9. The analysis of the impact data collected from Disaster Management Commission (DMC) of RGoZ, reveals a death toll of 8 people, damaging of ten electric poles (seven at Mwakaje and 3 Mwera) resulting into: 1) power shortage for several days; 2) trees and vegetation (Cassava plantation, banana and rice plantations to be affected. Moreover, results shows number of road culverts at Konde-Chake ${ }^{2}$ and Mwakaje roads (Figure 9) were either washed away by rushing water or damaged leading to long period strandment of transport services over different areas of Zanzibar. Also numbers of bridges including new Dr. Shein and Chamanagwe bridges (Figure 10 bottom right panel) were

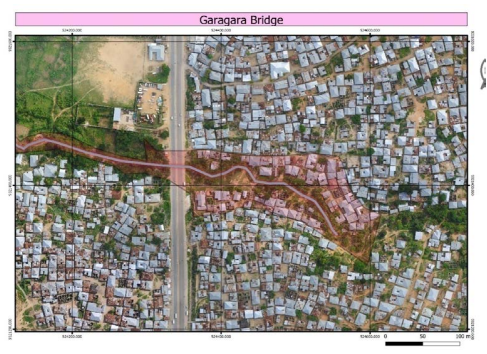

(a)

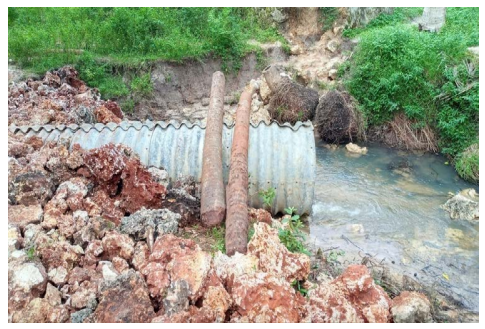

(c)

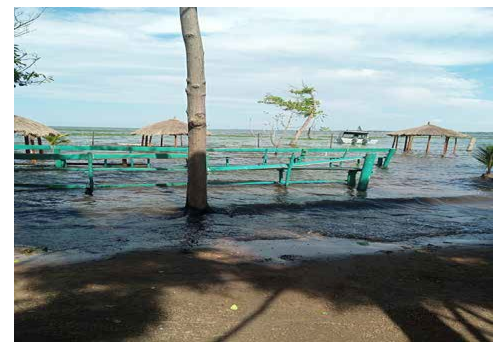

(e)

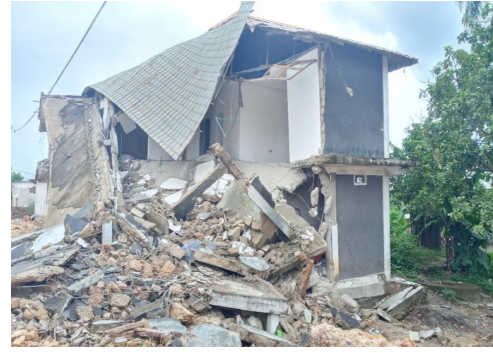

(b)

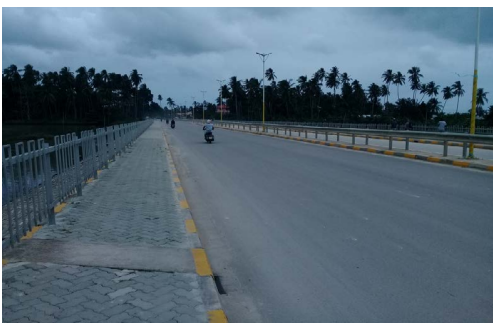

(d)

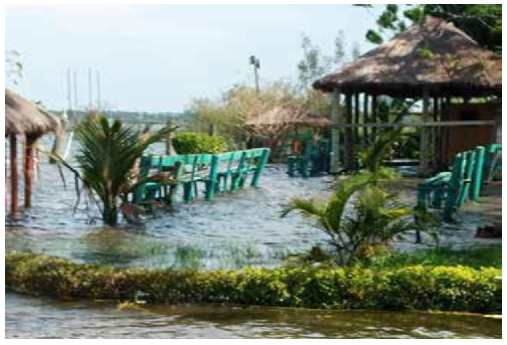

(f)

Figure 10. (a) affected area of by Mtopepo bridge; (b) Examples of broken house at Kihinani west B Unguja; (c) Calverts washed away by flooded rain water at Mwakaje; (d) the overflowed Dr. Shein bridge at s Mzaungu West A Zanzibar, where ((e) and (f)) are the submerged areas near lake Victoria shores (Source for Figures 10(a)-(d) is the DMC of the RGoZ in the $2^{\text {nd }}$ VPOs office, while for Figure 10(e) and Figure 10(f) is TMA (20202021)). 
overflow by water leading to either affecting the bridge edges or stranding transport services. Further results from DMC data analysis revealed that the flooding damages to the society were accelerated by illegal socioeconomic activities (e.g. sand mining on the edges of the bridges of culverts), ignorance to daily severe weather early warnings issued by TMA, building near river catchments and reserves among others.

Indeed, the East African Seasonal Monitor (EASM)

(https://reliefweb.int/report/world/east-africa-seasonal-monitor-may-5-2020) noted that MAM 2020 rains were mostly attributed to the sustained warmer than normal Indian Ocean, coupled with favorable atmospheric conditions over much of East of Africa. These rains results into significant societal impacts over the NCT and neighboring countries of Kenya, and Uganda. Among the impacts recorded in NCT and Tanzania at large include floods, crop damage, loss of lives, households and assets, increased water levels over Lake Victoria and Tanganyika TMA (2020-2021) leading to flooded islands Figure 10(e) and Figure 10(f) and reallocation of more than 1000 peoples. Also the EASM and the [25] climate reports noted that the observed water levels were highest on the 60-year local record, superseding the comparable lake levels recorded during the 1997/98 extreme El Niño event. Indeed, [25] climate status report noted that many activities undertaken near the lake (Victoria and Tanganyika) shores including fish markets, parks and beaches were affected, and many settlements near the lake shores were submerged Figure 10(e) and Figure 10(f). In Kenya, reports indicated that more than 116 people died and about 40,000 people had been displaced, while in Uganda, about 200 people were displaced near Lake Victoria and Lake Kyoga, and about 140,000 people were at risk of being displaced due to flash floods.

\section{Discussions, Conclusions and Recommendations}

\subsection{Discussions}

The spatial and temporal analysis of the performance of the MAM, 2020 rainfall and its societal implications to Zanzibar and NCT was analyzed using different climate parameters which indicated the influence of ocean-atmosphere interactions. The presented higher $\operatorname{SST}_{\mathrm{A}}\left(0.1^{\circ} \mathrm{C}-2.5^{\circ} \mathrm{C}\right)$ during March to May 2020 over the Somali coast, entire EA coastal waters and Mozambican channel, as well as two Islands of Zanzibar (Pemba and Unguja), indicate that most areas of SWIO were under warm conditions resulting into enough moisture advection from the ocean to the western coast of SWIO as agreed by [26] and the EA seasonal monitor report of May 2020 which noted that warmer Indian Ocean (IO) SSTs give rise to a weaker monsoonal circulation (in May) that was connected to moisture advection anomalies from the IO into the African continent. Moreover, presented higher $\mathrm{SST}_{\mathrm{A}}$ variations were in agreement with the surface wind direction (i.e., southeasterly flow) and then turn to be northeasterly to westerly and this agreement is well noted by [26] that MAM rainfall is linked with the zonal 
surface winds anomalies. Indeed, reference [26] noted that March and April rainfall anomalies are linked to zonal thermal contrast between the Indian Ocean and the Eastern African landmass, the argument which highly supports our finding. Besides, the presented correlation between the long-term (30 yrs) MAM rainfall over some stations in Zanzibar and area average $\mathrm{SST}_{\mathrm{A}}$ over Re, Rs and $\mathrm{Rm}$ indicates that southeasterly area-averaged winds from Rm (Northern Madagascar) had a significant impact on MAM rainfall in some stations of Zanzibar. The presented wind results as moisture transporting agents at 850 and $700 \mathrm{mb}$ during the MAM, 2020 are well agreed by [27] who noted that increased fetch of low-level moisture flux anomalies from the tropical IO can result in the increase in MAM rainfall over Tanzania. Moreover, [28] noted that increased rainfall over East Africa was associated with the occurrence of an anomalous cyclonic circulation over the Western Indian Ocean (WIO). As for the presented results in PRW during MAM, 2020 that high amount of PRW was deviating away from the coastal and a further Ocean ward shift of the PRW during May 2020 observes over the coastal line of Tanzania could be explained by the fact that the Masika rainfall is more influence by the southeasterly and easterly wind flow, which in turn results in more moisture advection over the Tanzanian coastal line, and these results are in agreement with [29] who noted that, westerly flow anomalies across East Africa are associated with anomalous PRW. Indeed, the presented high moisture (Rhum) during MAM, 2020 over the Tanzanian coastal strip and Zanzibar with higher moisture in the southern coast than over the north in March and higher moisture in northern coastal areas during April and shifting of moisture to further northern areas of the coastal strip (i.e., moisture variability in the season) are in agreement with the number of studies including [30] who noted an unstable advected moisture from the IO during MAM and OND (October to December) seasons. Also, references [31] and [32] noted that a moisture influx from Congo during MAM season. Indeed, [33] observed a poor relationship between rainfall and moisture in dry areas, implying that high moisture content may not necessarily results an increase in rainfall depending on the region. On the aspect of regional aspect [34] noted advected moisture convergence is observed to correlate with convection. On the other hand, it is known that EA is in the region which is dominated by the convective system.

The presented results of the spatial and temporal variability in OLR during March April and May 2020, indicating more convective activities associated with deep clouds over most areas of Zanzibar and NCT as a result of northward shifting of the convective activities from the south due northward indicating the propagation of the Inter Tropical Convergence Zone (ITCZ), are supported by a number of studies including [35] who noted that low (high) values of OLR indicate greater (less) cloudiness and convective activity, also [7] noted that OLR convective oscillations over the Tanzanian coast have some of the characteristic features of intraseasonal oscillations occurring in the tropics. 
The presented higher ocean net heat flux $\left(\mathrm{W} / \mathrm{m}^{2}\right)$ which shows the net different heat exchange processes at the ocean surface and which is responsible for evaporation [24] for the three months of MAM, 2020 mapped at the northern coastal areas, and northward propagation of the net heat flux to Somali coast decline the moisture over coastal Tanzania, Mozambican channel and East African Coastal Current (EACC) and the presented low net ocean heat flux from April through May 2020 indicate an increased SST $_{\mathrm{A}}$ over the coastal areas is supported by reference [24] that SST warming along with the surface wind changes resulted in negative heat flux tendencies.

The aforementioned weather parameter has highly influenced the MAM 2020 rainfall over the NCT and Zanzibar, in particular, to be of extraordinary (i.e., to break the record in both distribution and strength), and hence resulting in devastating socio-economic impacts (ranging from deaths to loss of properties and wealth. For instance, a heavy recorded downpour of $\geq 100 \mathrm{~mm}$ over all stations in Zanzibar and some stations including Matangatuani and Kizimbani agromet station to have rainfall ranged 560 to $1070 \mathrm{~mm}$ is an indication that rainfall during this season was abundant and well spread across and among stations with the highest record over the stations resident along the western side of the islands than those along the eastern as supported by [9]. Indeed, the essence of MAM, 2020 rainfall to have high contribution ranged from $(50 \%-280 \%)$ to the long-term seasonal and monthly mean, is an indication of the high performance of this rainfall season compared to others as shown by the results in Figure 8(c) that was leading the five consecutive MAM seasons of 2016 to 2019. As for the frequency of the occurrence of the severe weather events of the index ( $50 \mathrm{~mm} /$ day) during MAM 2020, the presented results of 89 events during MAM 2020 are higher than that presented by [19] for December 2019 to February 2020 (DJF), but both this study and that of [11] indicate that the areas (NCT and Zanzibar) are very common for the occurrence of severe weather events which brought significant impacts on society.

\subsection{Conclusions}

Based on the presented results and extensive discussions the study concludes the following:

1) The MAM, 2020 seasonal rainfall in Tanzania and Zanzibar, in particular, was among the extreme ones in the record, which was accelerated by the extreme wetness of the three consecutive seasons of MAM, 2019, OND, 2019 and JF (2020) of seasonal rainfall;

2) The spectrum of the high socioeconomic impacts (outcomes) associated with MAM, 2020 seasonal rainfall was well spread in all areas of Zanzibar and NCT leading to increased livelihood stress;

3) Inadequate follow-up of the TMA warning, ignorance of the government directives, and social loyalty were among the issues that accelerated the impacts to most areas in Zanzibar. 


\subsection{Recommendations}

The strength of the spatial and temporal societal impacts to the MAM, 2020 rainfall was accelerated by anthropogenic activities including in proper planning of the living areas, illegal environmental degradation activities, inadequate drainage systems and carelessness of the implementation of the municipal acts and regulations to hinder degrading of the environmental issues. Thus, this study recommends the following:

1) Reviewing of the residential areas and strictly abandoning buildings in low land areas;

2) Revising the environmental law and acts (imposing penalty) which may have loopholes of conducting illegal actives on the municipal environmental issues;

3) Restructuring the Zanzibar rural drainage systems to prevent flood in case of heavy downpours;

4) Conducting the cost-benefit analysis of the associated MAM, 2020 rainfall in Zanzibar as a tool for policymakers and regional managers to intervene in the high rainfall impacts and other related climate hazards;

5) Societal awareness on the impacts of severe weather events (e.g. tropical cyclones heavy rainfall and droughts) should be conducted country-wide to reduce the impacts associated with these events.

\section{Acknowledgements}

The authors would like to appreciate contributions from different institutions and individuals. First and foremost, the authors would like to send their thanks to the Reanalysis 1 data management programs for their good work of simulating the data and making them on open source bases for research work. TMA and DMC are highly thanked for the provision of climate and impact data free of charge. Lastly, I would like to send my sincere regards to my fellow staffs at the Zanzibar office and to my lovely wife, children and family members for their encouragement.

\section{Conflicts of Interest}

The authors declare no conflicts of interest regarding the publication of this paper.

\section{References}

[1] Nicholson, S.E. (2016) An Analysis of Recent Rainfall Conditions in Eastern Africa. International Journal of Climatology, 36, 526-532. https://doi.org/10.1002/joc.4358

[2] Anande, D. and Luhunga, P. (2019) Assessment of Socio-Economic Impacts of the December 2011 Flood Event in Dar es Salaam, Tanzania. Atmospheric and Climate Sciences, 9, 421-437. https://doi.org/10.4236/acs.2019.93029

[3] Chang'a, L.B., Kijazi, A.L., Mafuru, K.B., Nying'uro, P.A., Ssemujju, M., Deus, B., Kondowe, A.L., Yonah, I.B., Ngwali, M., Kisama, S.Y., Aimable, G., Sebaziga, J.N. 
and Mukamana, B. (2020) Understanding the Evolution and Socio-Economic Impacts of the Extreme Rainfall Events in March-May 2017 to 2020 in East Africa. Atmospheric and Climate Sciences, 10, 553-572. https://doi.org/10.4236/acs.2020.104029

[4] Kimani, M.W., Hoedjes, J.C.B. and Su, Z.B. (2019) Assessment of Moisture Distribution Influence on Rainfall Variability during Different Phases of IOD over East Africa. Journal of Geophysical Research Atmosphere. Under Review.

[5] Kabanda, T.A. and Jury, M.R. (1999) Inter-Annual Variability of Short Rains over Northern Tanzania. Climate Research, 13, 231-241. https://doi.org/10.3354/cr013231

[6] Mpeta, E.J. (2002) Mechanisms of Inter-Annual Rainfall Variability over Tropical Highlands of Africa and Its Predictability Potential. Thesis Submitted to the Department of Geography and Environmental Studies Faculty of Science, University of Zululand. http://www.meteo.go.tz/weather forecasts/seasonal-weather-forecast

[7] Kijazi, A.L. and Reason, C.J. (2005) Relationships between Intraseasonal Rainfall Variability of Coastal Tanzania and ENSO. Theoretical and Applied Climatology, 82, 153-176. https://doi.org/10.1007/s00704-005-0129-0

[8] Kai, K.H. (2018) Impacts of Southwestern Indian Ocean Tropical Cyclones and Storms on the Rainfall Pattern and Vegetation Productivity over Tanzania. Thesis Submitted to the Institute of Marine Sciences of the University of Dar Es Salaam, Dar Es Salaam, 297.

[9] Kai, K.H., Kijazi, A.L. and Osima, S.E. (2020) An Assessment of the Seasonal Rainfall and Its Societal Implications in Zanzibar Islands during the Season of October to December, 2019. Atmospheric and Climate Sciences, 10, 509-529. https://doi.org/10.4236/acs.2020.104026

[10] Li, C.J., Chai, Y.Q., Yang, L.S. and Li, H.R. (2016) Spatio-Temporal Distribution of Flood Disasters and Analysis of Influencing Factors in Africa. Natural Hazards, 82, 721-731. https://doi.org/10.1007/s11069-016-2181-8

[11] Kai, K.H., Osima, S.E., Kijazi, A.L., Ngwali, M.K. and Hamad, A.O. (2021) Assessment of the Off-Season Rainfall of January to February 2020 and Its Socio Economic Implications in Tanzania: A Case Study of the Northern Coast of Tanzania. Journal of Atmospheric Science Research, 4, 51-69. https://doi.org/10.30564/jasr.v4i2.3135

[12] TMA (Tanzania Meteorological Authority) (2019) The October to December (OND) Seasonal Forecast for Tanzania. http://www.meteo.go.tz/weather forecasts/seasonal-weather-forecast

[13] Chang'a, L.B., Kijazi, A.L., Mafuru, K.B., Kondowe, A.L., Osima, S.E., Mtongori, H.I., Ng'ongolo, H.K., Juma, O.H. and Michael, E. (2020) Assessment of the Evolution and Socio-Economic Impacts of Extreme Rainfall Events in October 2019 over the East Africa. Atmospheric and Climate Sciences, 10, 319-338. https://doi.org/10.4236/acs.2020.103018

[14] ICPAC (2019) Statement from the Fifty Third Greater Horn of Africa Climate Outlook Forum (ghacof53) for October to December, 2019 Rainfall Season: 26-28 August 2019; Hyatt Hotel, Dar es salaam, Tanzania.

[15] Mapande, A.T. and Reason, C.J.C. (2005) Links between Rainfall Variability on Intra-Seasonal and Inter-Annual Scales over Western Tanzania and Regional Circulation and SST Patterns. Meteorology and Atmospheric Physics, 89, 215-234. https://doi.org/10.1007/s00703-005-0130-2

[16] ICPAC (2020) Statement from the 54th Greater Horn of Africa Climate Outlook 
Forum (ghacof54) for March to May 2020 Rainfall Season: 27-29 January 2020. https://gallery.mailchimp.com/c0c3fc97a16d77359aa6419af/files/0ae729b6-8fdb-450 1-afd9-20ad43d07bb0/GHACOF54 Statement 2020.pdf?utm source=ICPAC NE WSLETTER\&utm campaign=b5a66119b6EMAIL CAMPAIGN 20190225064

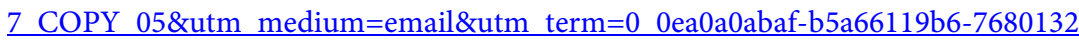
$\underline{1}$

[17] TMA (2020) The March to May, 2020 (MAM 2020) Seasonal Forecast for Tanzania.

[18] Mafuru, K.B. and Guirong, T. (2018) Assessing Prone Areas to Heavy Rainfall and the Impaction of the Upper Warm Temperature Anomaly during March-May Rainfall Season in Tanzania. Advances in Meteorology, 2018, Article ID: 8353296. https://doi.org/10.1155/2018/8353296

[19] Kai, K.H., Ngwali, M.K. and Faki, M.M. (2021) Assessment of the Impacts of Tropical Cyclone Fantala to Tanzania Coastal Line: Case Study of Zanzibar. Atmospheric and Climate Sciences, 11, 245-266. https://doi.org/10.4236/acs.2021.112015

[20] RGoZ (2007) An Assessment of Rainwater Harvesting Potential in Zanzibar. http://apps.worldagroforestry.org/downloads/O1E Assessment of Rainwater harv esting Potential in Zanzibar.pdf

[21] Josey, S., Kent, E. and Taylor, P. (1999) New Insights into the Ocean Heat Budget Closure Problem from Analysis of the SOC Air-Sea Flux Climatology. Journal of Climate, 12, 2856-2880. https://doi.org/10.1175/1520-0442(1999)012\%3C2856:NIITOH\%3E2.0.CO;2

[22] Wilks, D.S. (1995) Statistical Methods in the Atmospheric Sciences. 2nd Edition, International Geophysics Series, Vol. 59, Academic Press, 464 p.

[23] Wilks, D.S. (2006) Statistical Methods in the Atmospheric Sciences. Academic Press.

[24] Rahul, S. and Gnanaseelan, C. (2013) Net Heat Flux over the Indian Ocean: Trends, Driving Mechanisms, and Uncertainties. IEEE Geosciences and Remote Sensing Letters, 10, 776-780. https://doi.org/10.1109/LGRS.2012.2223194

[25] TMA (2020-2021) Statement on the Status of Tanzania Climate in 2020. https://www.meteo.go.tz/uploads/publications/sw1626330912-TMA\%20BOOK\%20 2020\%20-2021\%20(3).pdf

[26] Zorita, E. and Tilya, F.F. (2002) Rainfall Variability in Northern Tanzania in the March-May Season (Long Rains) and Its Links to Large-Scale Climate Forcing. Climate Research, 20, 31-40. https://doi.org/10.3354/cr020031

[27] Kijazi, A.L. and Reason, C.J.C. (2012) Intra-Seasonal Variability over the Northeastern Highlands of Tanzania. International Journal of Climatology, 32, 874-887. https://doi.org/10.1002/joc.2315

[28] Goddard, L. and Graham, N.E. (1999) Importance of the Indian Ocean for Simulating Rainfall Anomalies over Eastern and Southern Africa. Journal of Geophysical Research: Atmospheres, 104, 19099-19116. https://doi.org/10.1029/1999JD900326

[29] Mchugh, M.J. (2004) Near-Surface Zonal Flow and East African Precipitation Receipt during Austral Summer. Journal of Climate, 17, 4070-4079. https://doi.org/10.1175/1520-0442(2004)017\%3C4070:NZFAEA\%3E2.0.CO;2

[30] Yang, W., Seager, R., Cane, M.A. and Lyon, B. (2015) The Annual Cycle of East Africa Precipitation. Journal of Climatology, 28, 2385-2400.

https://doi.org/10.1175/JCLI-D-14-00484.1

[31] Camberlin, P. and Philippon, N. (2002) The East African March-May Rainy Season: Associated Atmospheric Dynamics and Predictability over the 1968-97 Period. Journal of Climate, 15, 1002-1019. 
https://doi.org/10.1175/1520-0442(2002)015\%3C1002:TEAMMR\%3E2.0.CO;2

[32] Camberlin, P. and Okoola, R.E. (2003) The Onset and Cessation of the "Long Rains" in Eastern Africa and Their Interannual Variability. Theoretical and Applied Climatology, 75, 43-54. https://doi.org/10.1007/s00704-002-0721-5

[33] Shi, F., Hao, Z. and Shao, Q. (2014) The Analysis of Water Vapor Budget and Its Future Change in the Yellow-Huai-Hai Region of China. Journal of Geophysical Research: Atmospheres, 119, 10702-10719. https://doi.org/10.1002/2013JD021431

[34] Xie, S., Zhang, Y., Giangrande, S.E., Jensen, M.P., McCoy, R. and Zhang, M. (2014) Interactions between Cumulus Convection and Its Environment as Revealed by the MC3E Sounding Array. Journal of Geophysical Research: Atmospheres, 119, 1178411808. https://doi.org/10.1002/2014JD022011

[35] Makarau, A. (1994) Intra-Seasonal Oscillatory Modes of the Southern Africa Summer Circulation. PhD Thesis, University of Cape Town, University of Cape Town. 